\title{
Oxidation Microstructure Studies of Reinforced Carbon/Carbon
}

\author{
Nathan S. Jacobson* \\ NASA Glenn Research Center \\ Cleveland, $\mathrm{OH} 44135$ \\ Donald M. Curry \\ NASA Johnson Space Center \\ Houston, TX 77058
}

Keywords: Carbon/carbon composites, Oxidation, Coating, Reactivity, Graphitic carbon

\begin{abstract}
Laboratory oxidation studies of reinforced carbon/carbon (RCC) are discussed with particular emphasis on the resulting microstructures. This study involves laboratory furnace $\left(500-1500^{\circ} \mathrm{C}\right)$ and arc-jet exposures $\left(1538^{\circ} \mathrm{C}\right)$ on various forms of RCC. RCC without oxidation protection oxidized at 800 and $1100^{\circ} \mathrm{C}$ exhibits pointed and reduced diameter fibers, due to preferential attack along the fiber edges. RCC with a SiC conversion coating exhibits limited attack of the carbon substrate at 500,700 and $1500^{\circ} \mathrm{C}$. However samples oxidized at 900,1100 , and $1300^{\circ} \mathrm{C}$ show small oxidation cavities at the $\mathrm{SiC} /$ carbon interface below through-thickness cracks in the SiC coating. These cavities have rough edges with denuded fibers and can be easily distinguished from cavities created in processing. Arc-jet tests at $1538^{\circ} \mathrm{C}$ show limited oxidation attack when the $\mathrm{SiC}$ coating and glass sealants are intact. When the $\mathrm{SiC} /$ sealant protection system is damaged, attack is extensive and proceeds through matrix cracks, creating denuded fibers on the edges of the cracks. Even at $1538^{\circ} \mathrm{C}$, where diffusion control dominates, attack is non-uniform with fiber edges oxidizing in preference to the bulk fiber and matrix.
\end{abstract}

\footnotetext{
* Corresponding Author: nathan.s.jacobson@nasa.gov , Phone 216-433-5498, FAX 216-433-5544
} 


\section{Introduction}

The oxidation of carbon has been studied extensively. Perhaps the most important conclusion from these studies is that the mechanism and microstructure of oxidation is highly dependent on the type of carbon [1]. Most studies of carbon oxidation focus on either the reaction mechanism/kinetics or the microstructural characteristics of attack, although the oxidation mechanism and the resultant microstructure are closely connected.

This report is on oxidation microstructures observed in the reinforced carbon/carbon (RCC) used for the thermal protection of the wing leading edge and nose cap of the Space Shuttle Orbiter. Consider first unprotected carbon/carbon. There is extensive literature on the oxidation of these materials [2-7]. Oxidation begins to be significant above about $500^{\circ} \mathrm{C}$. Previous studies indicate oxidation is controlled by the chemical reaction of carbon and oxygen below about $700-800^{\circ} \mathrm{C}$ and both chemical reaction and gas-phase diffusion above about $700-800^{\circ} \mathrm{C}[2,5]$. Surface reaction rates are quite dependent on the type of carbon, so selective attack of the higher energy surfaces is expected. Attack is typically along the fiber axis at the fiber/matrix interface [3]. Crystalline or graphitic carbon is less susceptible to oxidation $[6,8]$. Fibers derived from polyacrylonitrile (PAN) polymers [8] are more crystalline in the interior than the edges and hence the interior is more oxidation resistant than the edges. Oxidation creates a pointed morphology on such fibers $[5,6]$. The rayon-derived fibers in RCC are expected to behave similarly.

The conclusions from oxidation studies of carbon fiber/SiC matrix composites [8,9] are also useful in understanding oxidation of RCC. Halbig and Cawley [9] show that reaction control at $750^{\circ} \mathrm{C}$ leads to more uniform attack deep into the substrate; whereas diffusion control at $1250^{\circ} \mathrm{C}$ leads to attack around the edges of the specimen.

The structure of RCC has been described in detail elsewhere $[10,11]$. RCC is protected from oxidation via a conversion coating of SiC. Due to the different coefficients of 
thermal expansion between carbon and $\mathrm{SiC}$, through-thickness cracks develop in the $\mathrm{SiC}$ coating. Several sealants are applied to fill these cracks. At the highest temperatures, the $\mathrm{SiC}$ conversion coating should be in compression and the cracks and fissures close. Ideally the sealants are fluid and fill the cracks and fissures as well. However, in nonideal conditions and at lower temperatures, cracks and fissures may be open and provide pathways for oxidation. The authors have done a series of experiments with intentionally drilled holes through the $\mathrm{SiC}$, leading to oxidation-created cavities below the $\mathrm{SiC}$ coating [12] at 600,1000 , and $1400^{\circ} \mathrm{C}$. At $600^{\circ} \mathrm{C}$ attack was minimal; however at 1000 and $1400^{\circ} \mathrm{C}$ oxidation cavities formed at a rate described by a diffusion model.

This paper reports on a series of controlled oxidation experiments on RCC with emphasis on the microstructure of oxidation damage in the carbon/carbon substrate. Oxidation damage in unprotected RCC, protected RCC with coating cracks, and protected RCC with coating damage is discussed. The objectives of this paper are two-fold (1) Relate the post-oxidation microstructure to mechanism (2) Identify distinguishing features of oxidation-induced porosity as compared to porosity from fabrication.

\subsection{Experimental: Starting Materials}

A schematic of RCC is shown in Fig. 1. The substrate consists of a two-dimensional layup of rayon-derived carbon fabric. Fibers perpendicular to the direction of the particular cut are referred to as 'longitudinal' and the fibers parallel to the direction of the cut are referred to as 'transverse'. Porosity in the carbon/carbon substrate is filled with repeated application of a liquid carbon precursor $[10,11]$. As noted, oxidation protection is afforded by the formation of a $\mathrm{SiC}$ conversion coating. The cracks in the $\mathrm{SiC}$ are sealed with a vacuum infiltration of tetra-ethyl silicate (TEOS), which decomposes to $\mathrm{SiO}_{2}$ on heating. Two applications of an outer coating of a sodium silicate-based glass (Type A Sealant) are applied for additional protection. 


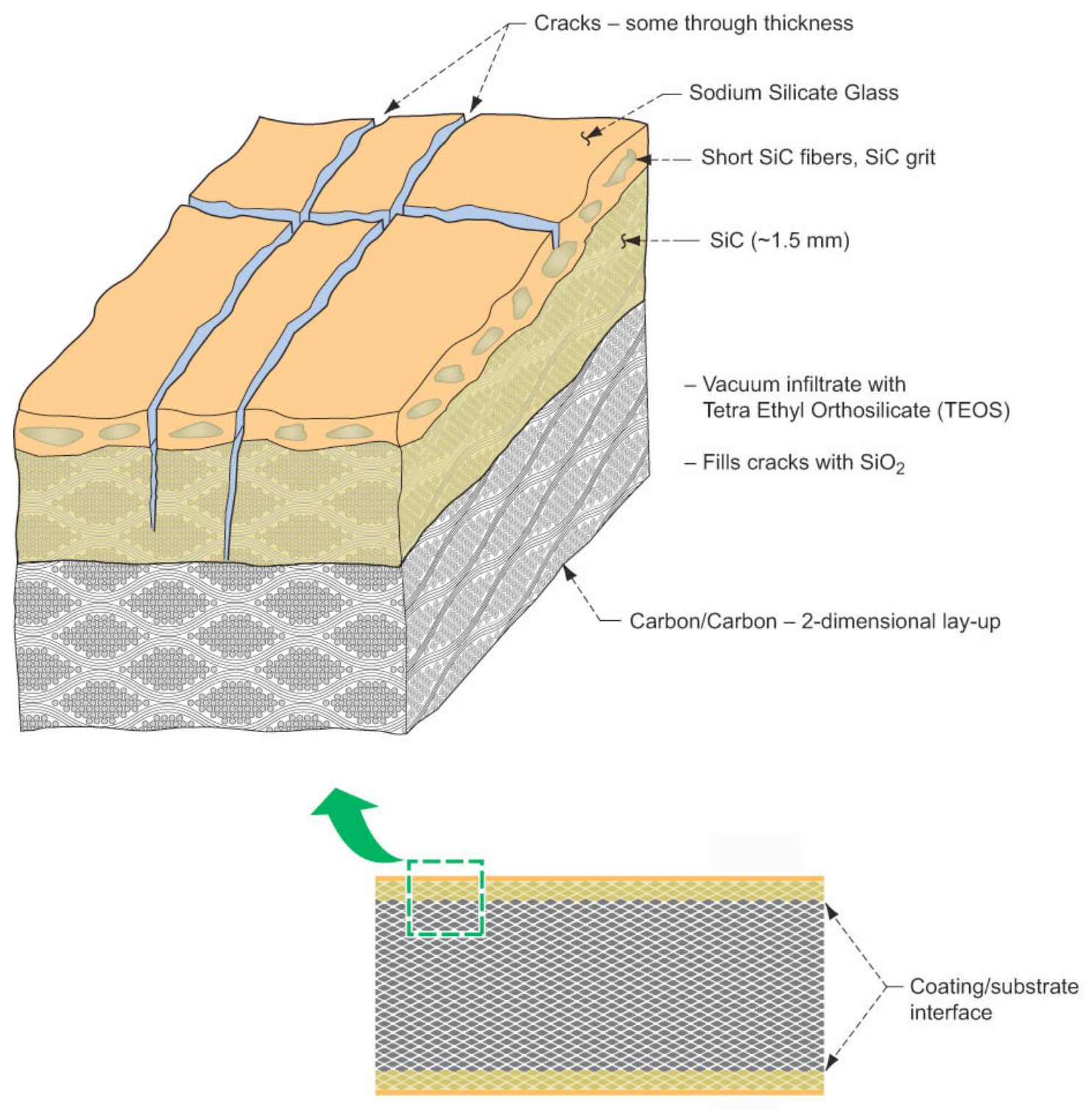

CD-05-82747

Figure 1. Schematic of RCC. 
Three variants of RCC are studied here, as listed in Table 1. Each one taken after a different processing step in manufacturing. This selection of samples permits a study of the influence of each added component on oxidation.

Table 1. RCC materials studied.

\begin{tabular}{|l|l|}
\hline Designation & Material \\
\hline RCC-P3 & $\begin{array}{l}\text { C/C substrate with three liquid carbon precursor } \\
\text { infiltrations }\end{array}$ \\
\hline RCC-P3/SiC & $\begin{array}{l}\text { C/C substrate with three liquid carbon precursor } \\
\text { infiltrations, SiC conversion coating }\end{array}$ \\
\hline RCC-P3/SiC/TEOS/Sealant & $\begin{array}{l}\text { C/C substrate with three liquid carbon precursor } \\
\text { infiltrations, SiC conversion coating, two sodium silicate } \\
\text { glass sealant applications }\end{array}$ \\
\hline
\end{tabular}

Figs. 2(a)-(c) illustrate the appearance of the as-fabricated material. Fig. 2(a) is an electron micrograph of the as-cut RCC P-3, showing both transverse and longitudinal fiber bundles. Fig. 2(b) is an optical micrograph of the RCC P-3/SiC material, illustrating typical voids and cracks through the fiber bundles produced in processing. Fig. 2(c) is a higher magnification photo illustrating a void from processing. Voids form from incomplete compaction and shrinkage of the matrix material. 


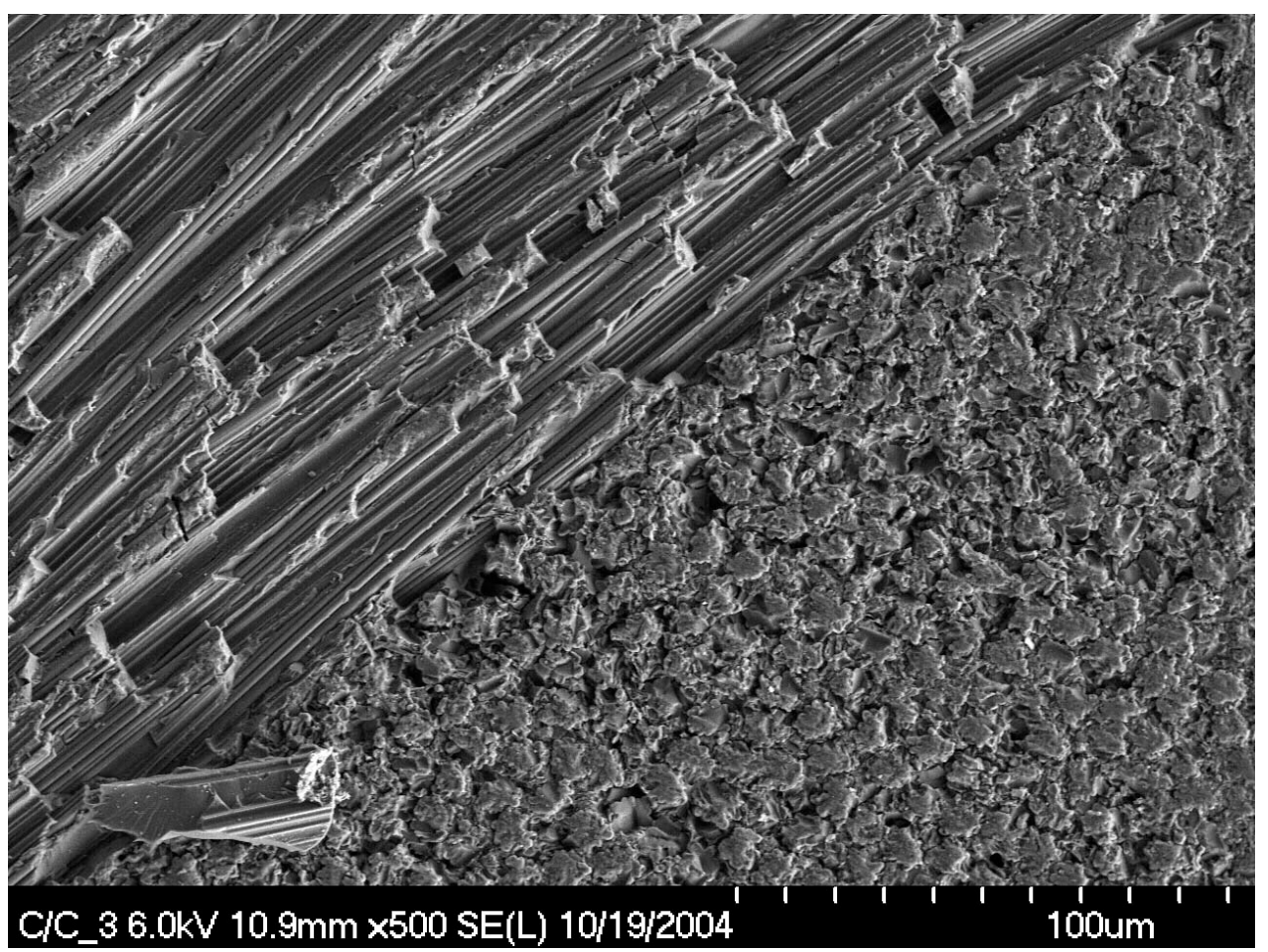

Figure 2(a). RCC-P3 before oxidation, showing both transverse and longitudinal fibers. 


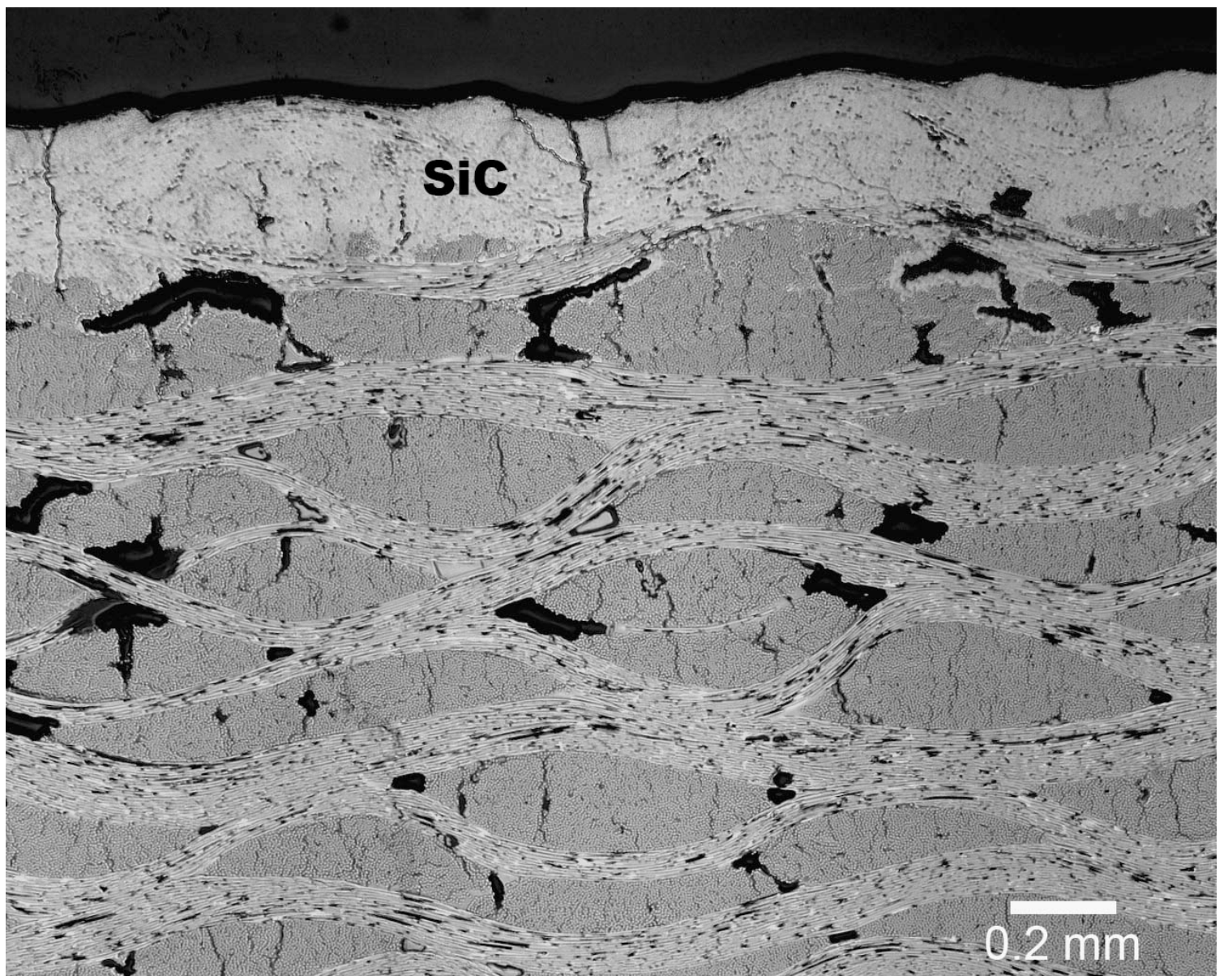

Figure 2(b) Cross-sectional view of as fabricated RCC P-3/SiC. 


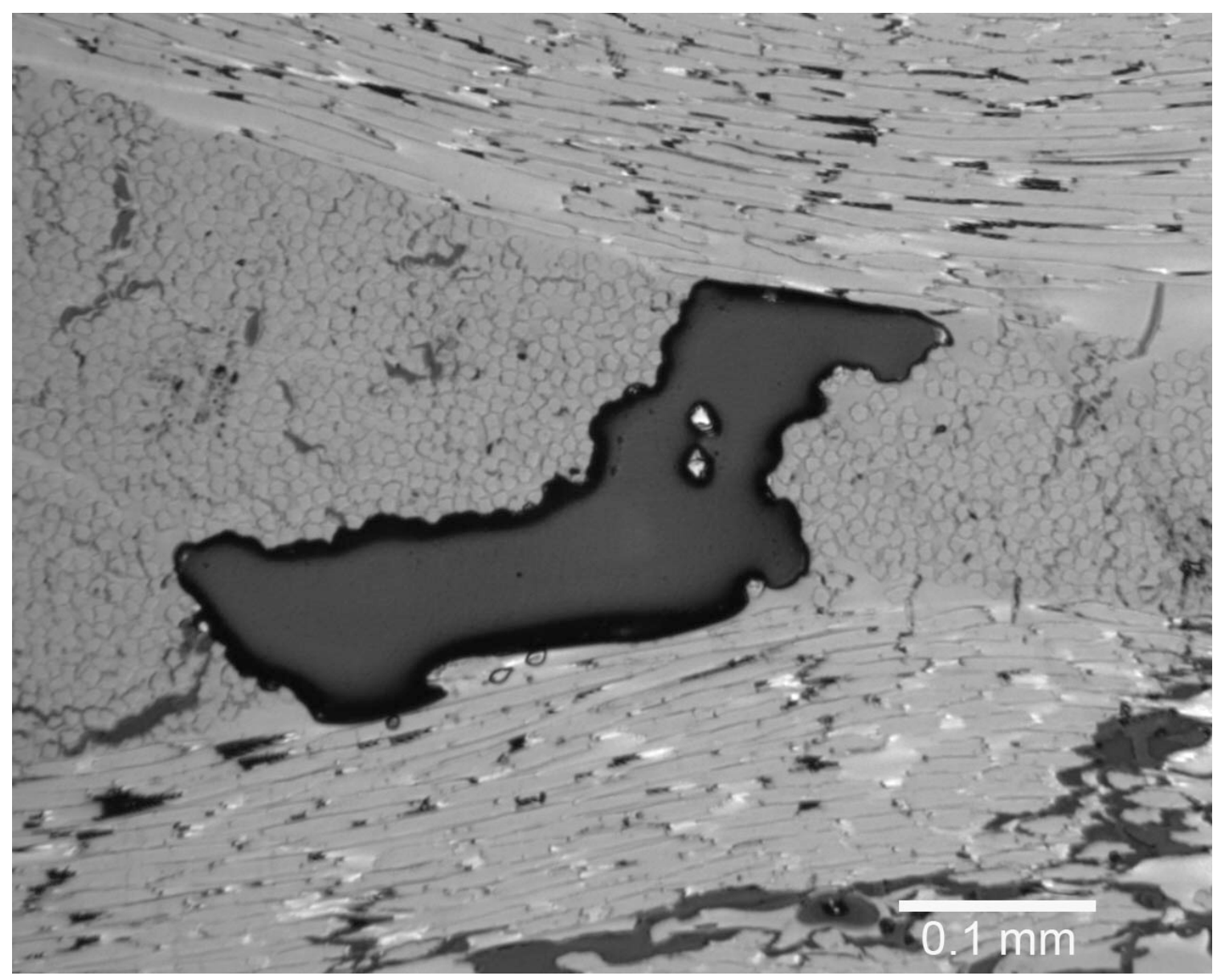

Figure 2(c).Cross-sectional view of a pore from fabrication in RCC P-3/SiC + TEOS.

\subsection{Experimental: Oxidation Exposures and Microstructural Examination}

Specimens were oxidized in either a reduced pressure laboratory tube furnace at the NASA Glenn Research Center or the arc-jet facility at the NASA Johnson Space Center (JSC). The reduced pressure laboratory tube furnace has been described elsewhere [12] and is shown schematically in Fig. 3. Using the vacuum pump and needle valves shown, it was possible to obtain excellent pressure control to $667 \pm 13 \mathrm{~Pa}$ ( $5 \pm 0.1$ torr), which is representative of the pressure encountered in the Orbiter's re-entry to the earth's atmosphere. Gas flowing at about $100 \mathrm{cc} / \mathrm{min}$ STP was used. Typically controlled tests were done by heating in $\mathrm{Ar}$ (the $\mathrm{MoSi}_{2}$ heating elements reached temperature in 30 minutes), switching to air for a specified hold time, and cooling in Ar. 


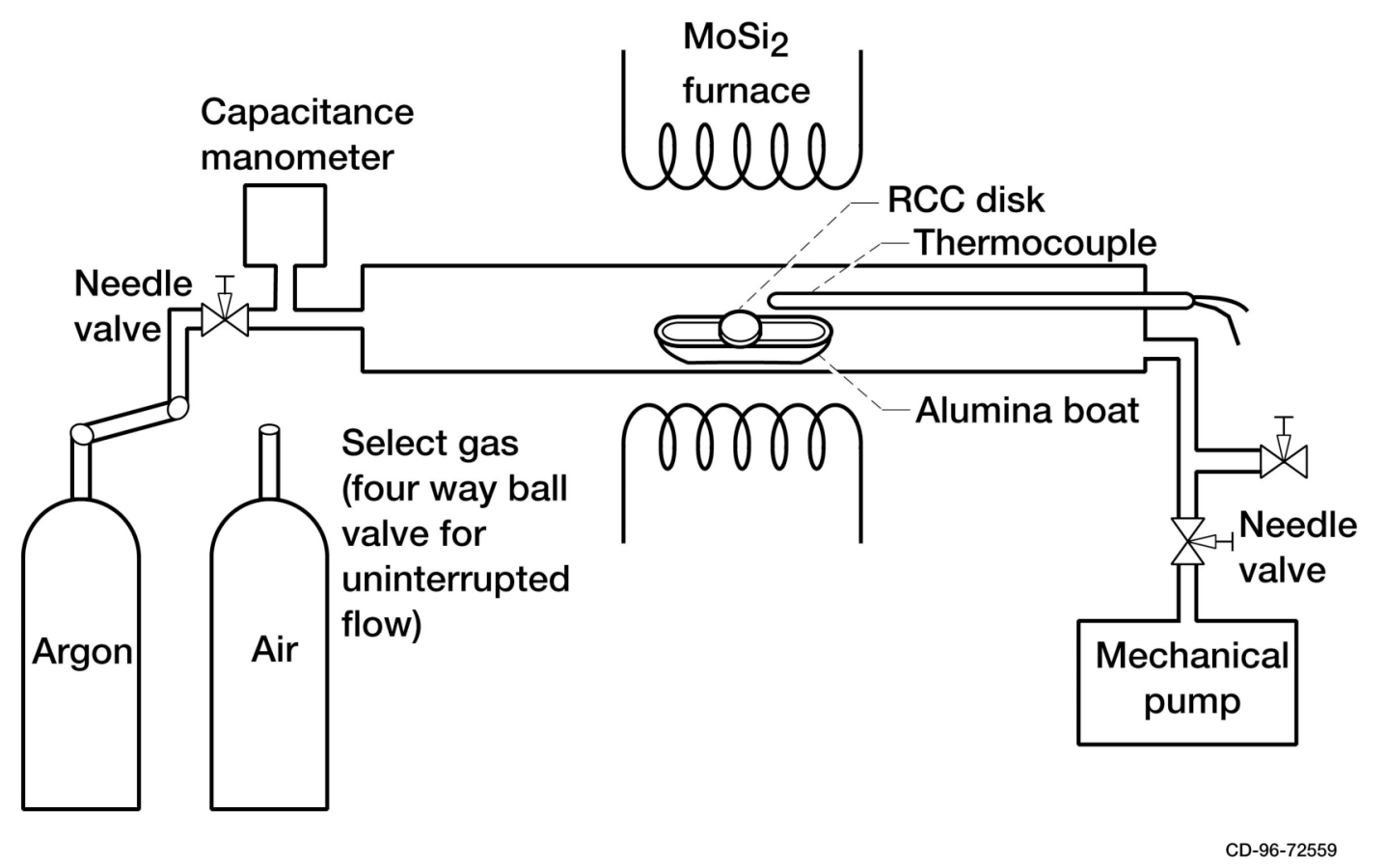

Figure 3. Schematic of reduced pressure laboratory furnace.

The arc-jet facility at JSC has been described in detail elsewhere $[13,14]$. This large facility is for simulation of re-entry conditions. Air is electrically heated and expanded through a channel or conical nozzle. This creates a high flux of dissociated molecules on the standard $7.1 \mathrm{~cm}$ (2.8 inch) diameter RCC discs.

Cross sections of all specimens were examined. The uncoated RCC-P3 specimens were characterized without additional preparation using a Field Emission Scanning Electron Microscopy (FE-SEM, Model S4700, Hitachi). The coated specimens were sectioned, mounted with high pressure epoxy infiltration technique, polished and examined with optical microscopy (Reichert MeF3A, Optronics). 


\subsection{Results and Discussion: Laboratory Oxidation of RCC-P3}

Small cubes of RCC-P3 $(\sim 0.5 \mathrm{~cm}$ sides $)$ were cut with a diamond saw and oxidized in the reduced pressure tube furnace as described in Table 2.

Table 2. Oxidation of RCC-P3.

\begin{tabular}{|l|l|l|}
\hline Temperature $\left({ }^{\circ} \mathrm{C}\right)$ & Conditions & $\begin{array}{l}\text { Percent weight } \\
\text { change }\end{array}$ \\
\hline 500 & 5 torr air/0.5 hr & -2.2 \\
\hline 800 & 5 torr air/0.5 hr & -27.0 \\
\hline 1100 & 5 torr air/0.5 hr & -68.6 \\
\hline
\end{tabular}

Figs. 4-6 show views of the carbon/carbon after each treatment. After the $500^{\circ} \mathrm{C}$ treatment, the sample showed limited oxidation, as indicated by the small weight change. The surface after oxidation (Fig. 4) is similar to the surface before treatment (Fig. 2(a)). 


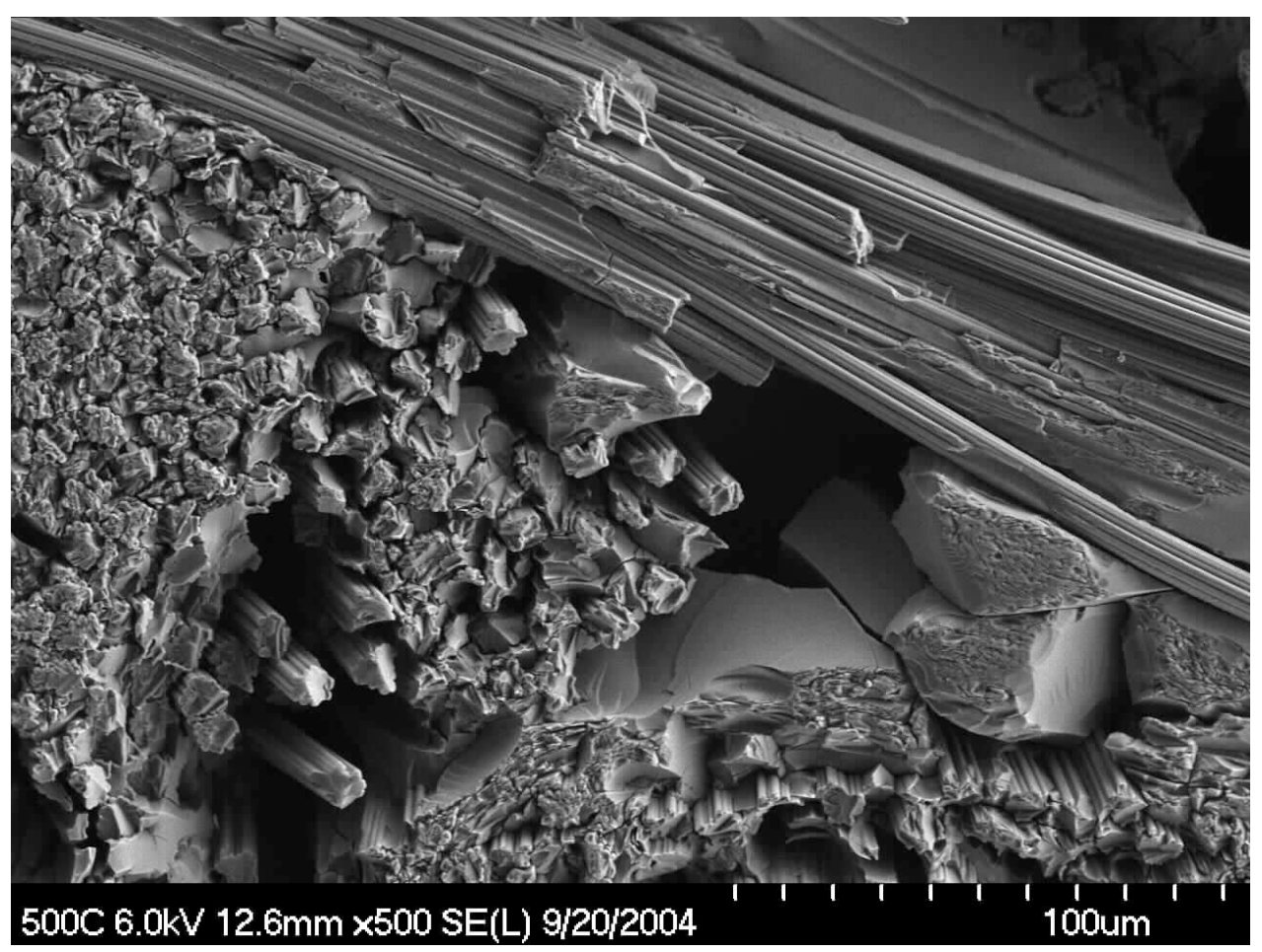

Figure 4. Exposed edge of RCC-P3 oxidized at $500^{\circ} \mathrm{C}$ for $0.5 \mathrm{hr}$

At $800^{\circ} \mathrm{C}$ and $1100^{\circ} \mathrm{C}$, substantial oxidation occurs as indicated by the weight loss (Table 2) and microstructure. These samples exhibited considerable macroscopic shrinkage. An overall view of the specimen oxidized at $800^{\circ} \mathrm{C}$ is shown in Fig. 5(a). Note that attack, as evidenced by thinning of the fiber bundles, is uniform throughout the entire width of the specimen, suggesting reaction control of the oxidation process [9]. Fig. 5(b) is a higher magnification view of the fibers. Both longitudinal and transverse fibers exhibit a reduced diameter (denuded) as compared to the fibers before oxidation (Fig. 2(a)). Cut fibers in the longitudinal direction show the 'pointed morphology' due to preferential oxidation at the fiber/matrix interface as opposed to the center or bulk of the fiber $[5,6]$. Note also the matrix carbon is absent, suggesting preferential oxidation of the matrix over the fibers. 


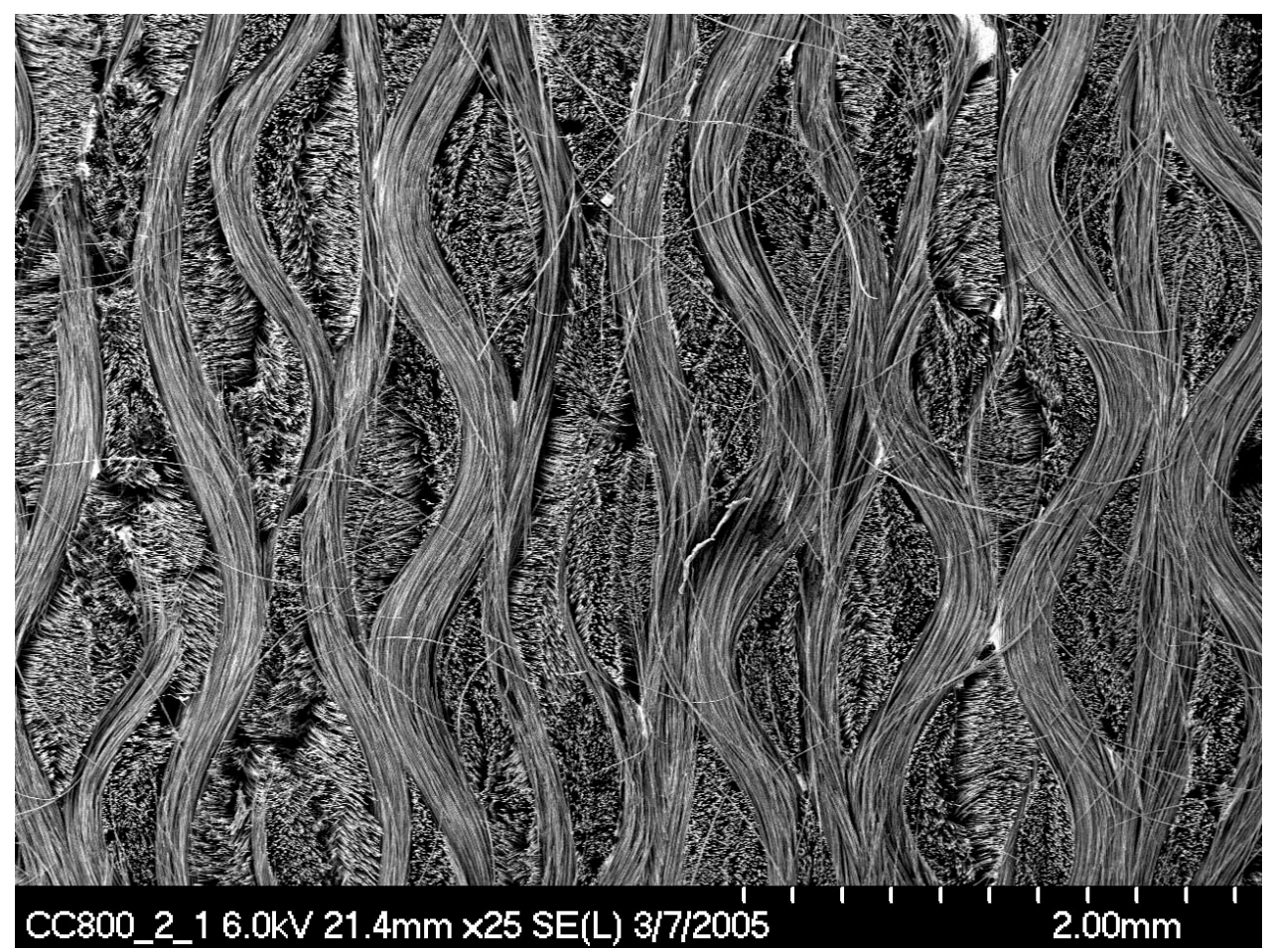

Figure 5(a). Overall view of RCC-P3 after oxidation for $0.5 \mathrm{hr}$ at $800^{\circ} \mathrm{C}$. This view

includes roughly the entire width of the specimen. Note the uniform attack throughout the specimen. 


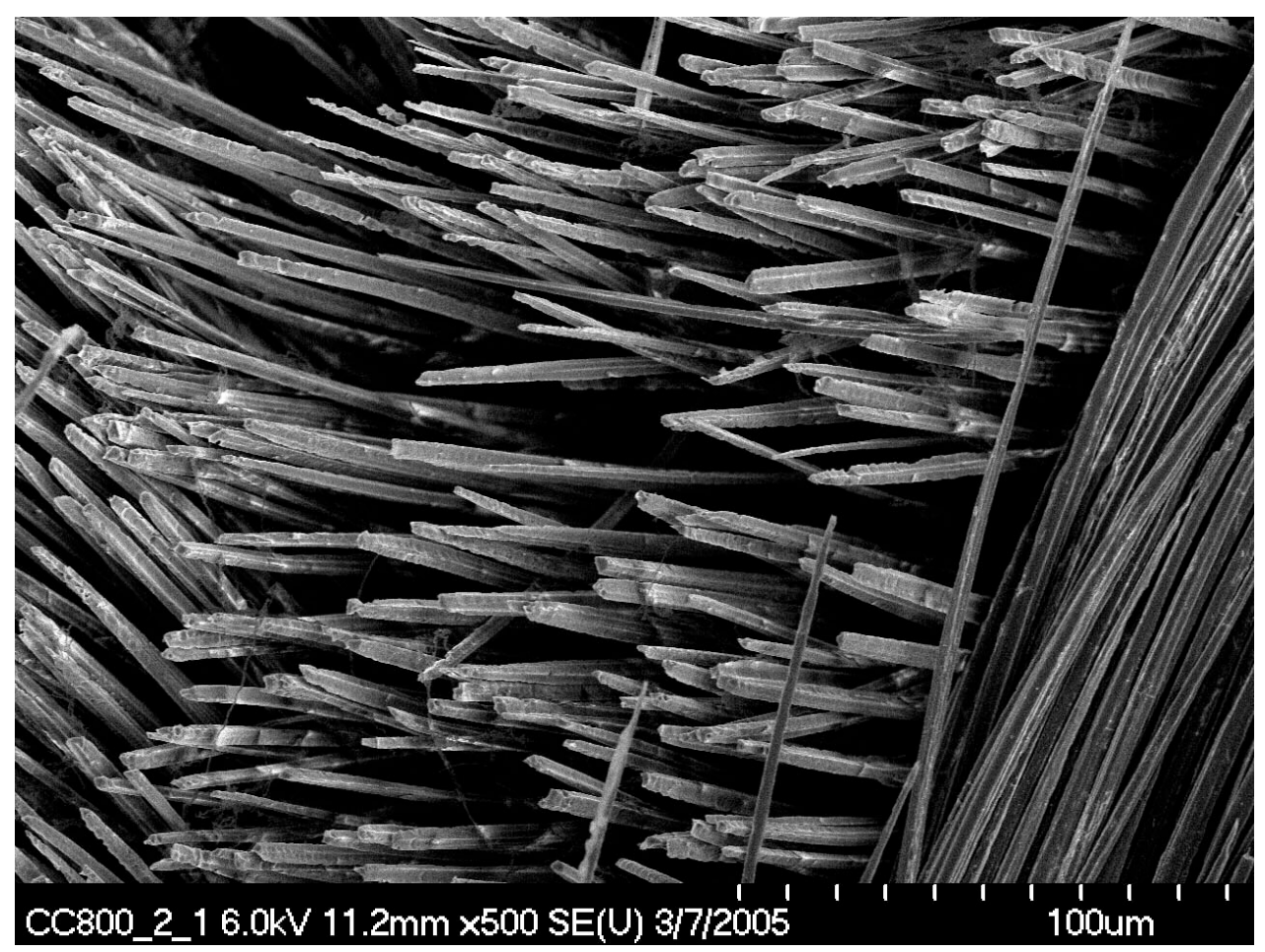

Figure 5(b). RCC-P3 after oxidation at $800^{\circ} \mathrm{C}$ for $0.5 \mathrm{hr}$. Note the denuded fibers and pointed ends.

Fig. 6(a) is an overall view of the specimen oxidized at $1100^{\circ} \mathrm{C}$. Note the sample appears denser in the center and oxidative damage appears concentrated at the edges, which suggests diffusion control of the oxidation process [9]. Fig. 6(b) shows the denuded and pointed fibers. It may be that that the more pronounced points on the $1100^{\circ} \mathrm{C}$ sample (Fig. 6(b)) as compared to the $800^{\circ} \mathrm{C}$ sample (Fig. 5(b)) are due to the higher temperatures. Fig. 6(c) shows a high magnification photo of the transverse fibers near an edge. Note that fibers are denuded, pointed at the ends, and also exhibit some degree of pitting. Again it appears the matrix carbon is removed via oxidation. 


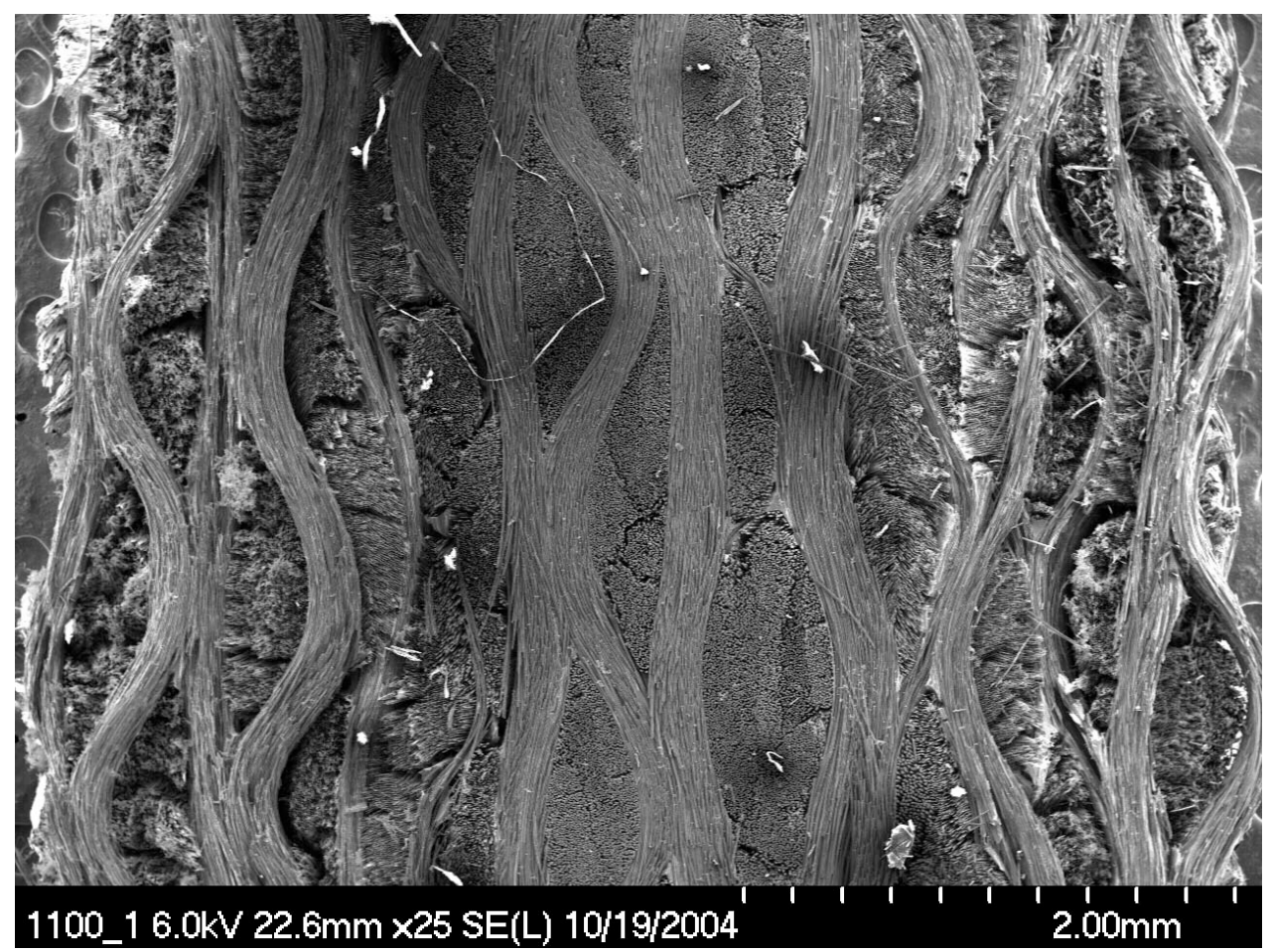

Figure 6(a). Overall view of RCC-P3 after oxidation for $0.5 \mathrm{hr}$ at $1100^{\circ} \mathrm{C}$. This view includes roughly the entire width of the specimen. Note the more localized attack on the two sides of the specimen. 


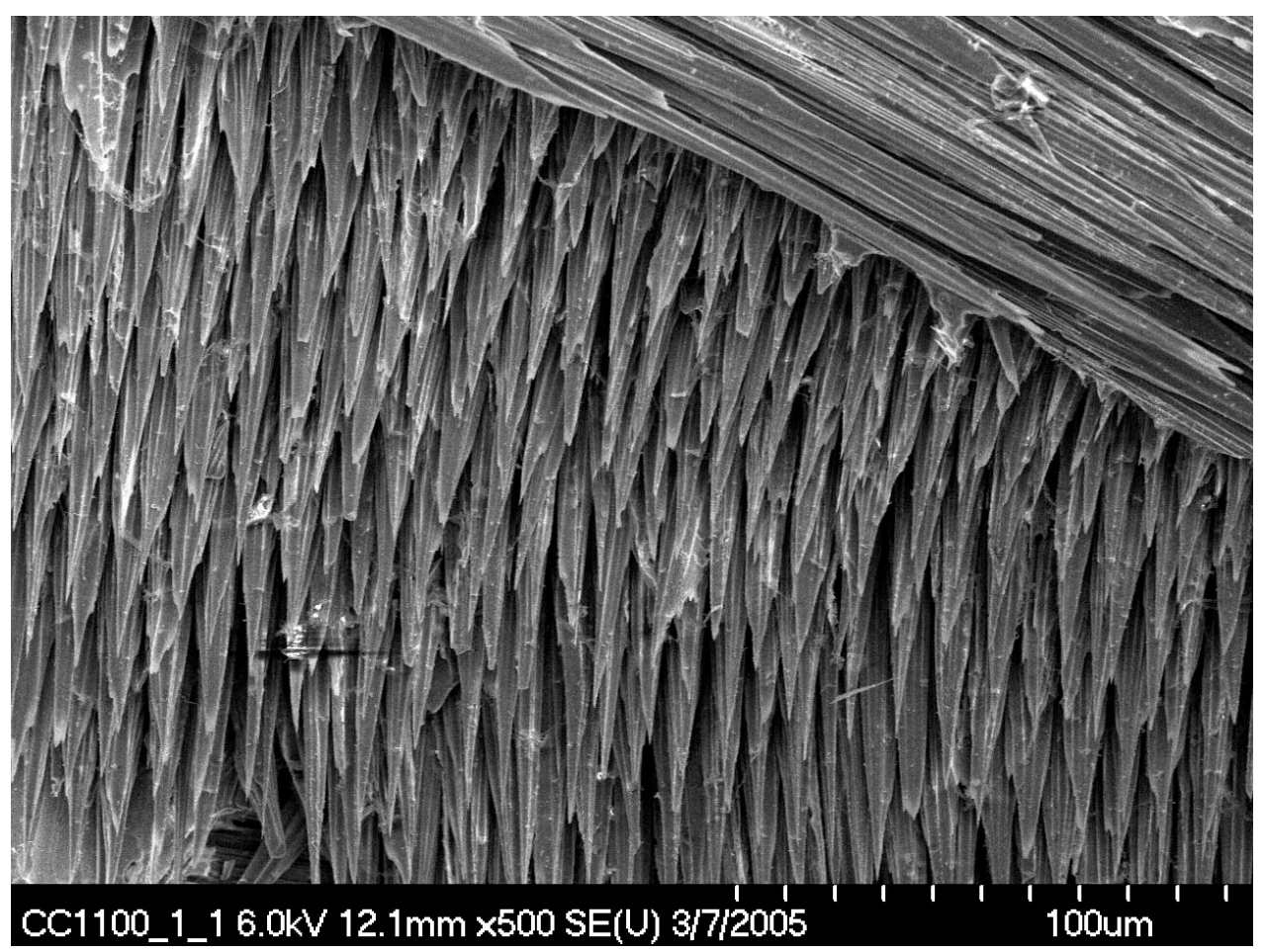

Figure $6(\mathrm{~b})$. RCC-P3 after oxidation at $1100^{\circ} \mathrm{C}$ for $0.5 \mathrm{hr}$. Note clear points on the ends of the longitudinal fibers. 


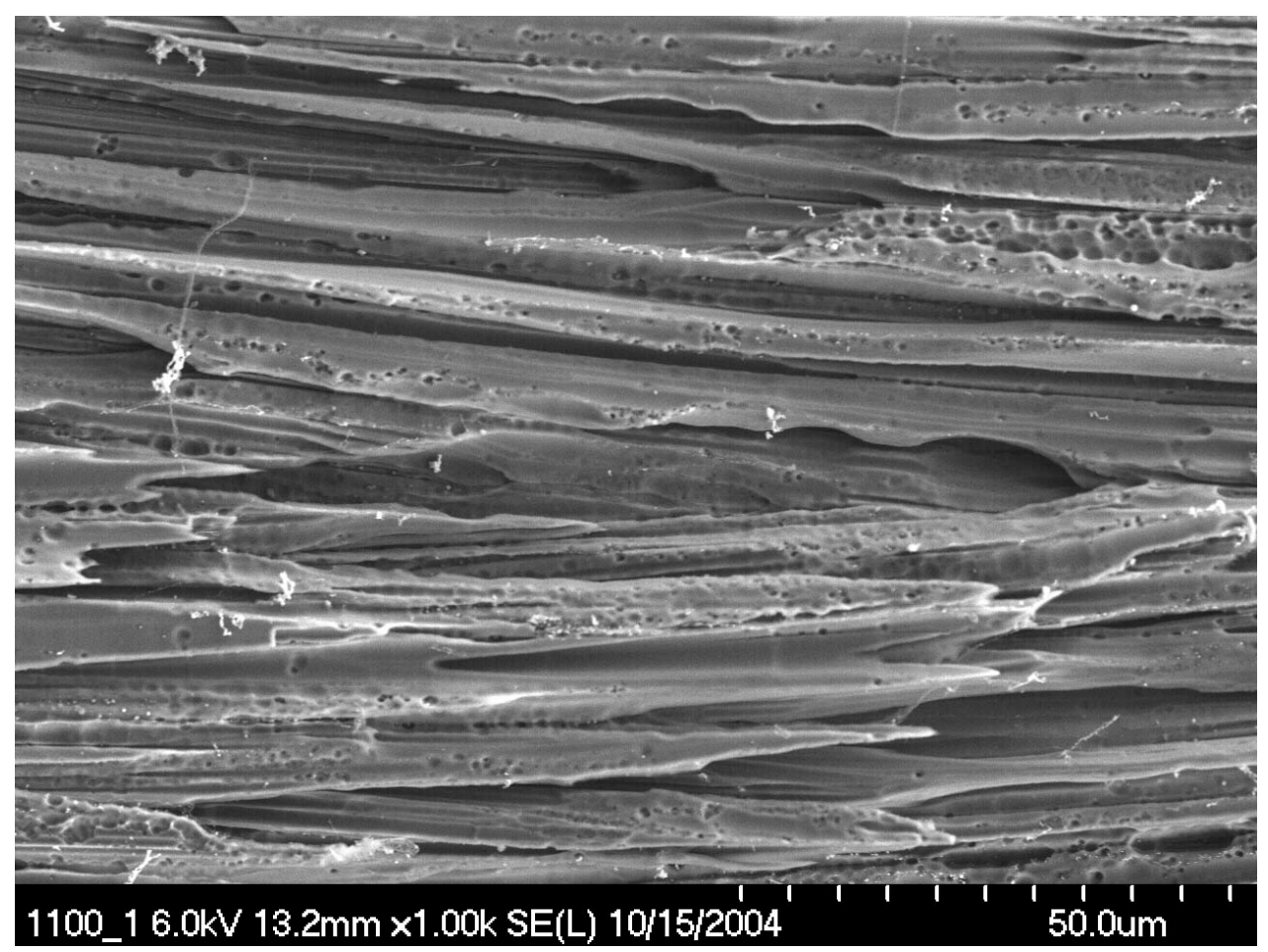

Figure 6(c). RCC-P3 after oxidation at $1100^{\circ} \mathrm{C}$ for $0.5 \mathrm{hr}$. Note the points at the fiber ends and pitting of the fibers.

\subsection{Results and Discussion: Laboratory oxidation of RCC-P3/SiC}

$\mathrm{RCC}-\mathrm{P} 3 / \mathrm{SiC}$ samples were in the form of $\sim 1.9 \mathrm{~cm}$ diameter $\mathrm{x} 0.5 \mathrm{~cm}$ thick buttons with all faces coated with SiC. Specimens were oxidized under the conditions of $1 \mathrm{hr} / 667 \mathrm{~Pa}$ air at 500, 700, 900, 1100, 1300, and $1500^{\circ} \mathrm{C}$. Two specimens were oxidized under each condition. Table 3 summarizes the results from these exposures. 
Table 3. Summary of observed oxidation effects for RCC-P3/SiC in $667 \mathrm{~Pa}$ of slowly flowing air for $1 \mathrm{~h}$.

\begin{tabular}{|c|c|c|c|c|}
\hline \multirow[t]{2}{*}{$\operatorname{Temp}\left({ }^{\circ} \mathrm{C}\right)$} & \multirow[t]{2}{*}{$\begin{array}{l}\text { Percent wt } \\
\text { change }\end{array}$} & \multicolumn{2}{|l|}{$\begin{array}{l}\text { Cross Section: } \\
\text { One Face }\end{array}$} & \multirow[t]{2}{*}{ Observations } \\
\hline & & $\begin{array}{l}\text { Number of through } \\
\text { thickness cracks } \\
\text { in } \mathrm{SiC} \text { coating }\end{array}$ & $\begin{array}{l}\text { Number of through } \\
\text { thickness cracks with } \\
\text { oxidation-induced cavities }\end{array}$ & \\
\hline 1500 & $-3.34 \pm 0.57$ & 16 & $1-2 ?$ & $\begin{array}{l}\text { Limited oxidation along } 1 \text { or } 2 \\
\text { continuations of cracks in } \mathrm{SiC} \text { into } \\
\text { the substrate-see text }\end{array}$ \\
\hline 1300 & $0.36 \pm 0.24$ & 10 & 3 & Clear cavities \\
\hline 1100 & $0.25 \pm 0.12$ & 14 & 3 & Clear cavities \\
\hline 900 & $-0.22 \pm 0.01$ & 11 & 1 & -- \\
\hline 700 & $-0.19 \pm 0.02$ & 16 & $1 ?$ & No clear oxidation damage \\
\hline 500 & $-0.16 \pm 0.01$ & 15 & -- & No clear oxidation damage \\
\hline
\end{tabular}

There are several processes occurring: 1) Weight gain due to oxidation of $\mathrm{SiC}$, which would be enhanced over baseline high purity $\mathrm{SiC}$ due the impurities in this system [15].

2) Weight loss due to oxidation of carbon. 3) Weight loss due to formation and loss of a liquid scale.

One sample from each condition was sectioned down the center with a diamond saw mounted and polished. In the $1500^{\circ} \mathrm{C}$ case, two samples were sectioned and prepared for characterization Microstructures were examined with an optical microscope to $\sim 500 \mathrm{X}$ and clearly showed the individual carbon fibers as well as voids. Each of the throughthickness cracks in the $\mathrm{SiC}$ coating were examined. Table 3 lists the approximate numbers of through-thickness cracks and presence or absence of cavities below the cracks. This is only an estimate from one polished section and only cracks readily visible at $25 \mathrm{X}$ magnification. 
First consider the $1500^{\circ} \mathrm{C}$ samples. The large weight loss shown in Table 3 suggests oxidation of the carbon substrate. Yet microstructural examination of cross sections of two specimens oxidized under these conditions indicated limited oxidation. Most of the through-thickness cracks did not lead to any clear oxidation damage, as shown in Fig. 7. On each cross section there were only one or two through-thickness cracks which led to limited evidence of oxidation. The is illustrated in Fig. 8, where a few denuded carbon fibers were found near the base of crack. No large oxidation cavities were observed. It is likely that the $1500^{\circ} \mathrm{C}$ sample shows very limited oxidation due to (1) Growth of a protective silica layer (2) Closure of $\mathrm{SiC}$ cracks due to the CTE differences.

The $1500^{\circ} \mathrm{C}$ sample did show the greatest weight loss of any of the samples studied (Table 3). Upon a removal from the furnace, this specimen had a visibly large amount of white-colored oxide. Further, the sample holder had a clear deposit of solidified glass. It is quite likely that the various metallic impurities known to exist in RCC [13] led to enhanced oxidation of $\mathrm{SiC}$. Note the thick silica layer in Fig. 7. Some of the oxide must have formed a low melting silicate and dripped or spalled off, leading to the observed weight loss. 


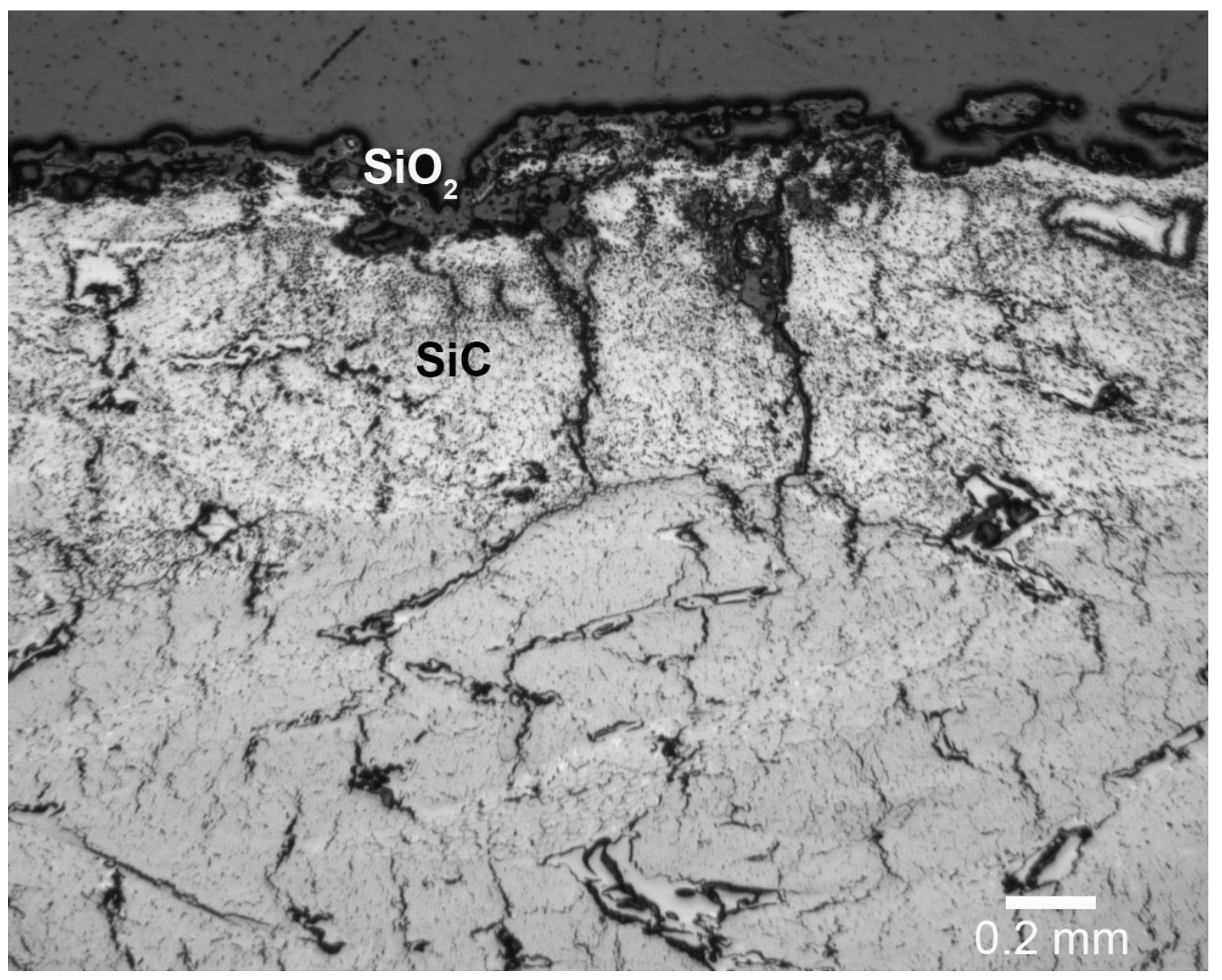

Figure 7. Through-thickness cracks in the RCC-P3/SiC sample oxidized at $1500^{\circ} \mathrm{C}$ for 1

hr. Note the thick silica layer on the surface. 


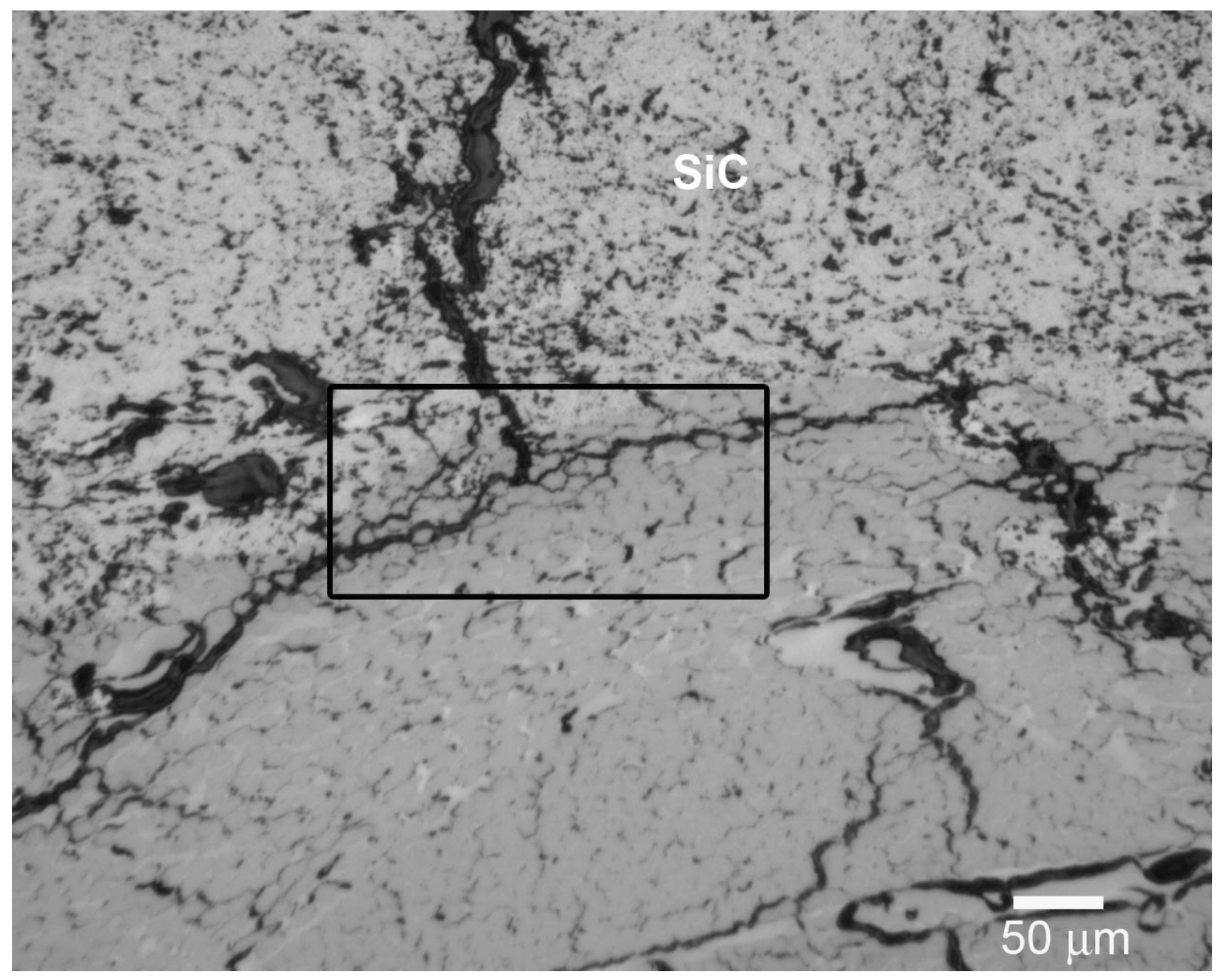

Figure 8. Possible oxidation attack from through-thickness crack in the RCC-P3/SiC sample oxidized at $1500^{\circ} \mathrm{C}$ for $1 \mathrm{hr}$.

The $1300^{\circ} \mathrm{C}$ sample showed more oxidation effects. Here there were three throughthickness cracks which led to oxidation cavities. These are shown in Figs 9(a)-(d). Fig. 9(a) shows an oxidation cavity in both the transverse and longitudinal fiber bundles. In Figs. 9(b) and 9(c) the oxidation cavity is in the transverse fibers and a small cavity is formed with attack along the walls of the fibers. Finally Fig. 9(d) shows a cavity formed in a transverse fiber bundle in line with the crack. Note the wedge-shaped appearance of the cavity, which may be due to the $\mathrm{SiC}$ through-thickness crack (oxidation path) corresponding to the portion of the weave where the transverse fiber bundle splits. 


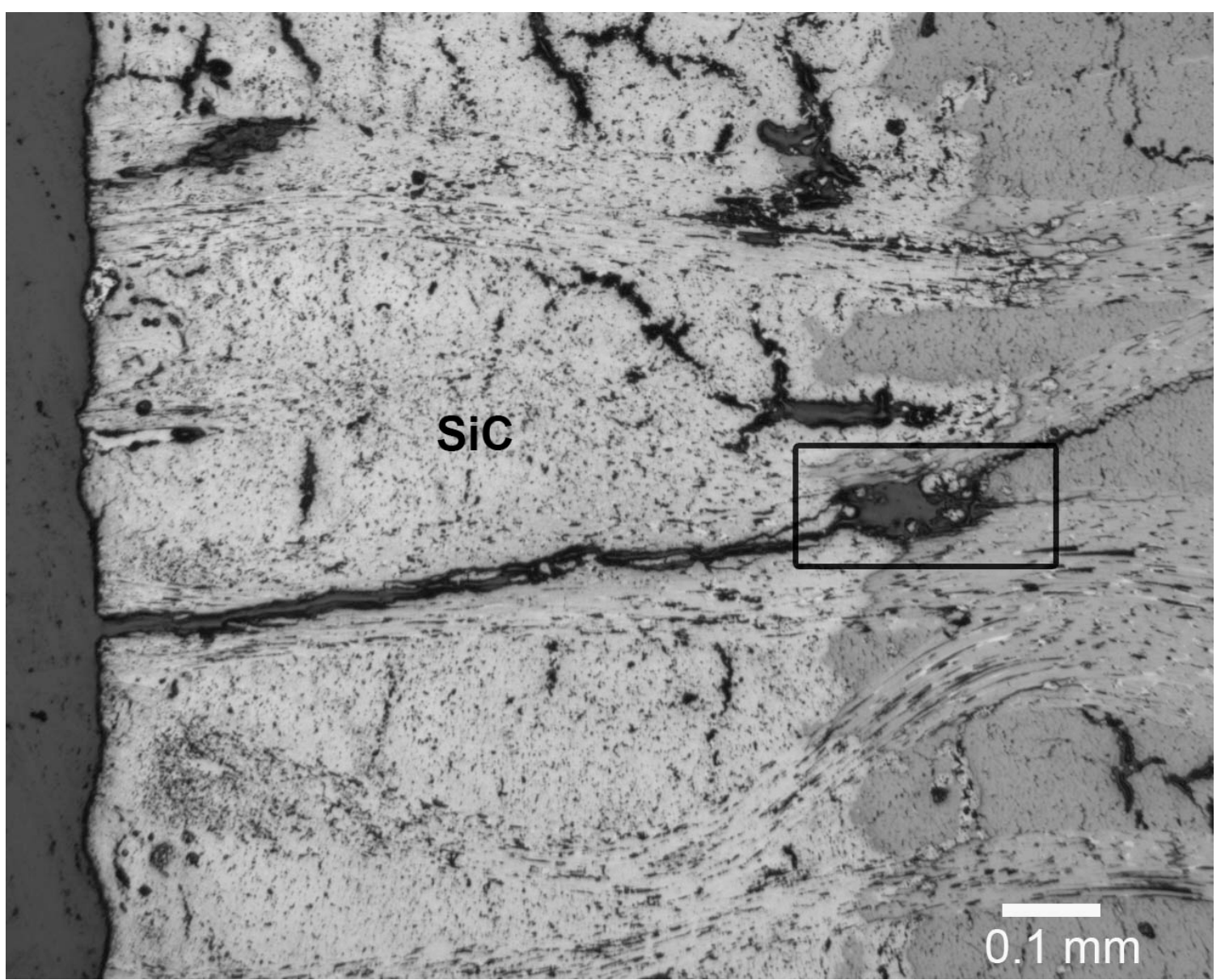

Figure 9(a). Oxidation cavity formed below through-thickness crack in $\mathrm{SiC}$ coating in $\mathrm{RCC}-\mathrm{P} 3 / \mathrm{SiC}$ oxidized for $1 \mathrm{~h}$ at $1300^{\circ} \mathrm{C}$. 


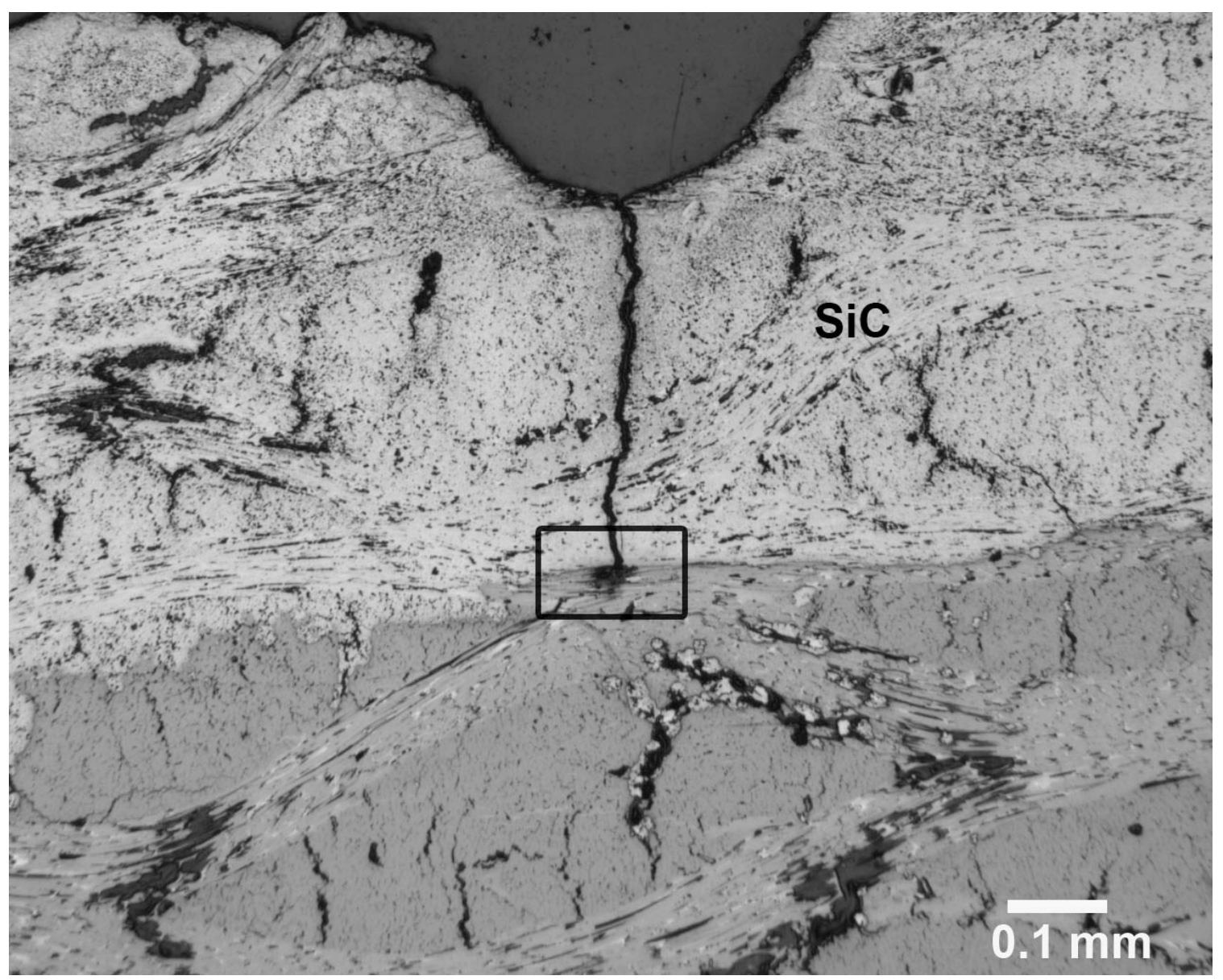

Figure 9(b). Oxidation cavity formed below through-thickness crack in $\mathrm{SiC}$ coating in $\mathrm{RCC}-\mathrm{P} 3 / \mathrm{SiC}$ oxidized for $1 \mathrm{~h}$ at $1300^{\circ} \mathrm{C}$. at $1300^{\circ} \mathrm{C}$. 


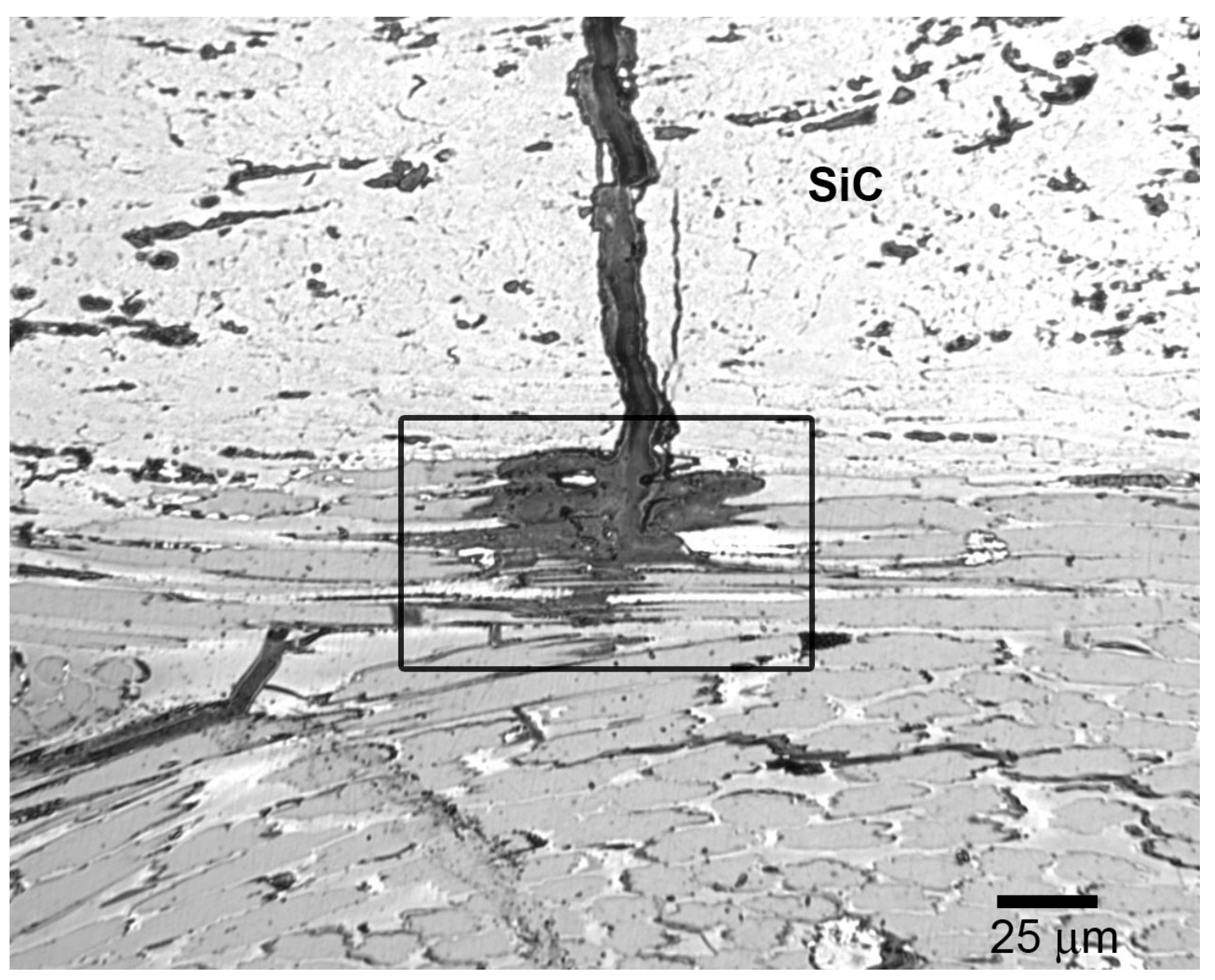

Figure 9(c). Enlargement of oxidation cavity in Fig. 9(b) formed below through-thickness crack in $\mathrm{SiC}$ coating in $\mathrm{RCC}-\mathrm{P} 3 / \mathrm{SiC}$ oxidized for $1 \mathrm{~h}$ at $1300^{\circ} \mathrm{C}$.. 


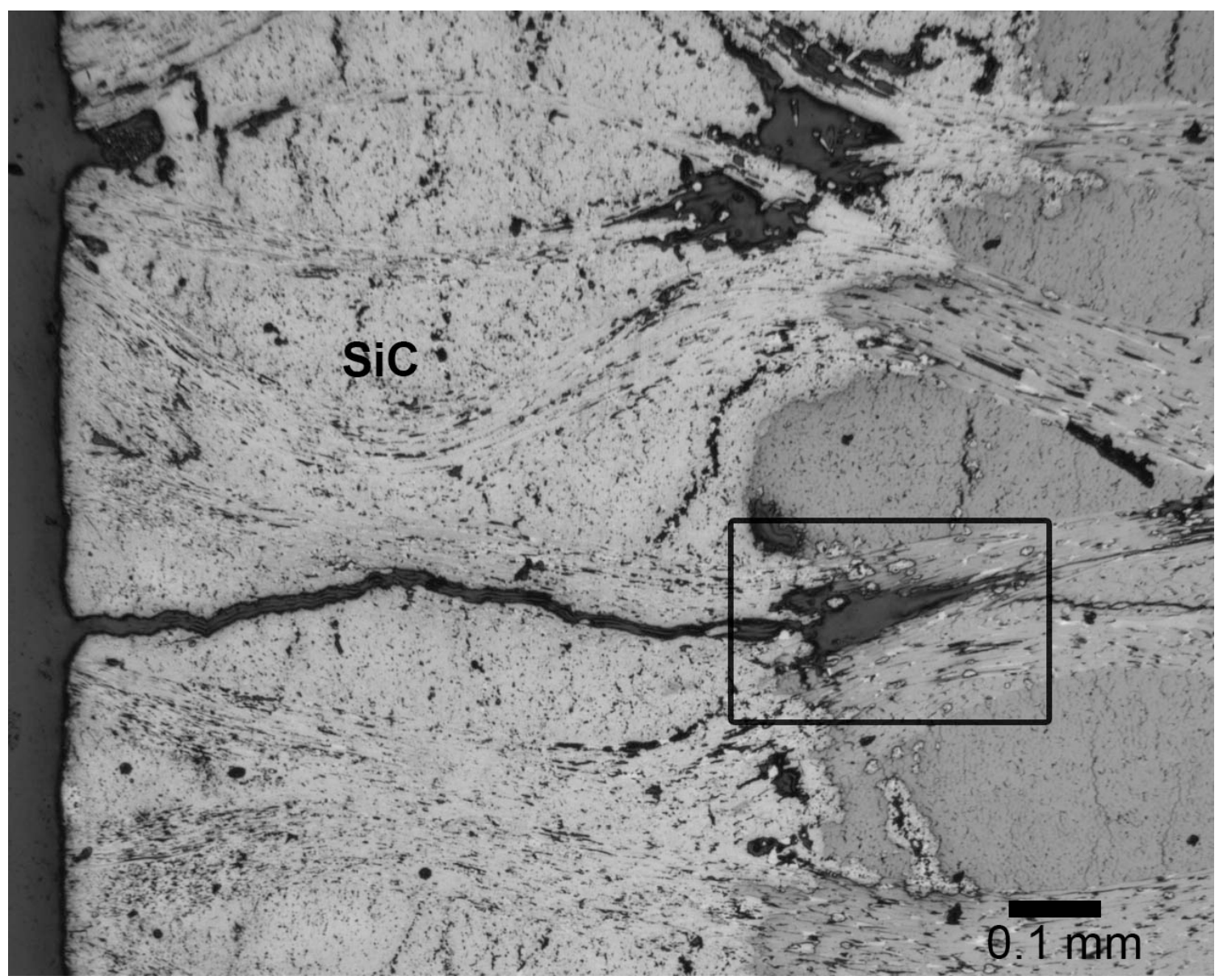

Figure 9(d). Oxidation cavity formed below through-thickness crack in SiC coating in $\mathrm{RCC}-\mathrm{P} 3 / \mathrm{SiC}$ oxidized for $1 \mathrm{~h}$ at $1300^{\circ} \mathrm{C}$.

The sample oxidized at $1100^{\circ} \mathrm{C}$ also showed oxidation cavities below through-thickness cracks. These are shown in Figs. 10(a)-(c). Note in Fig. 10(a) there is some oxidation along the edges of the fiber. Fig. 10(b) shows the outlines and reduction in diameter of individual fibers, as discussed previously. 


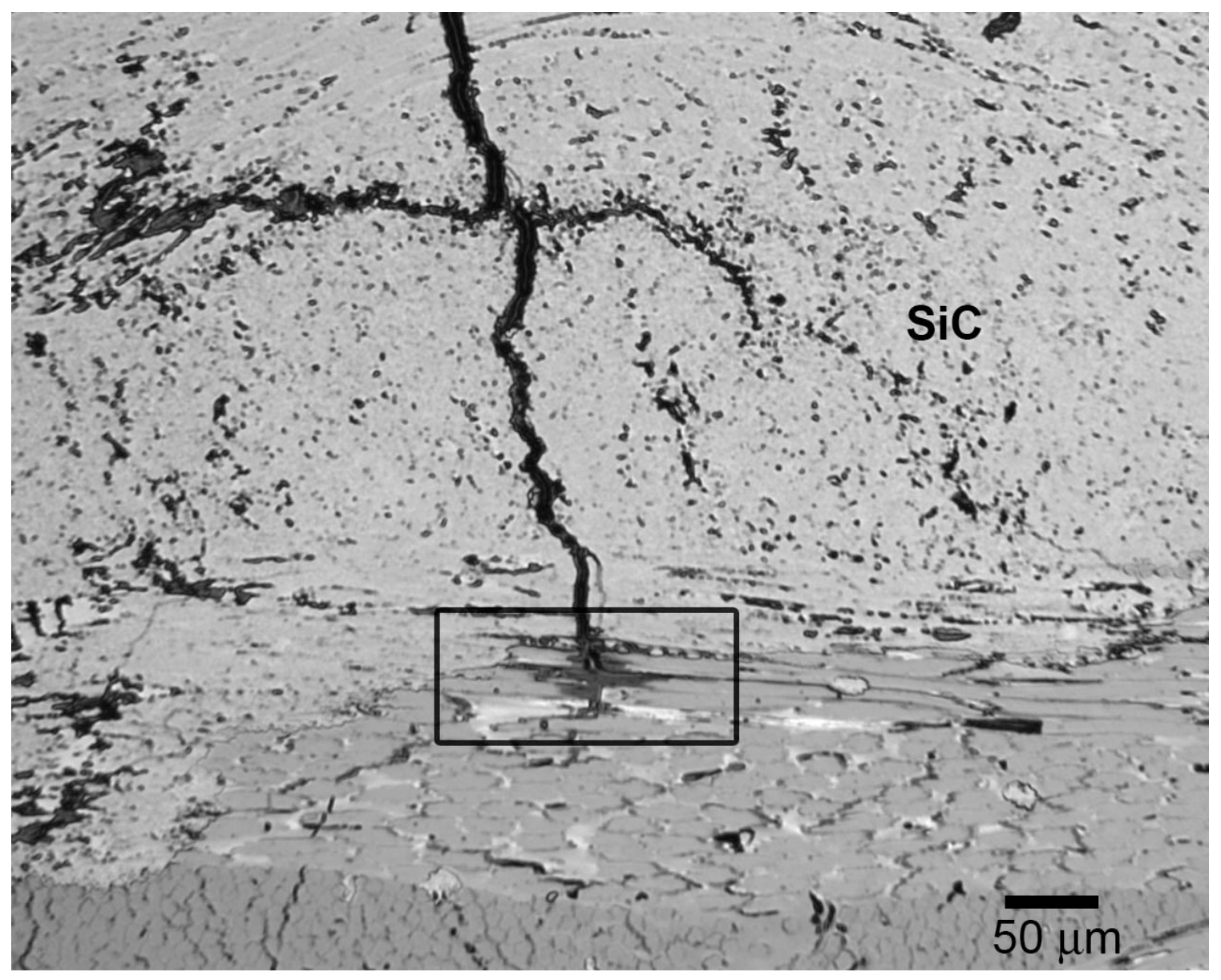

Figure 10(a). Oxidation cavity in a transverse fiber bundle for RCC-P3/SiC oxidized at $1100^{\circ} \mathrm{C}$ for $1 \mathrm{~h}$. 


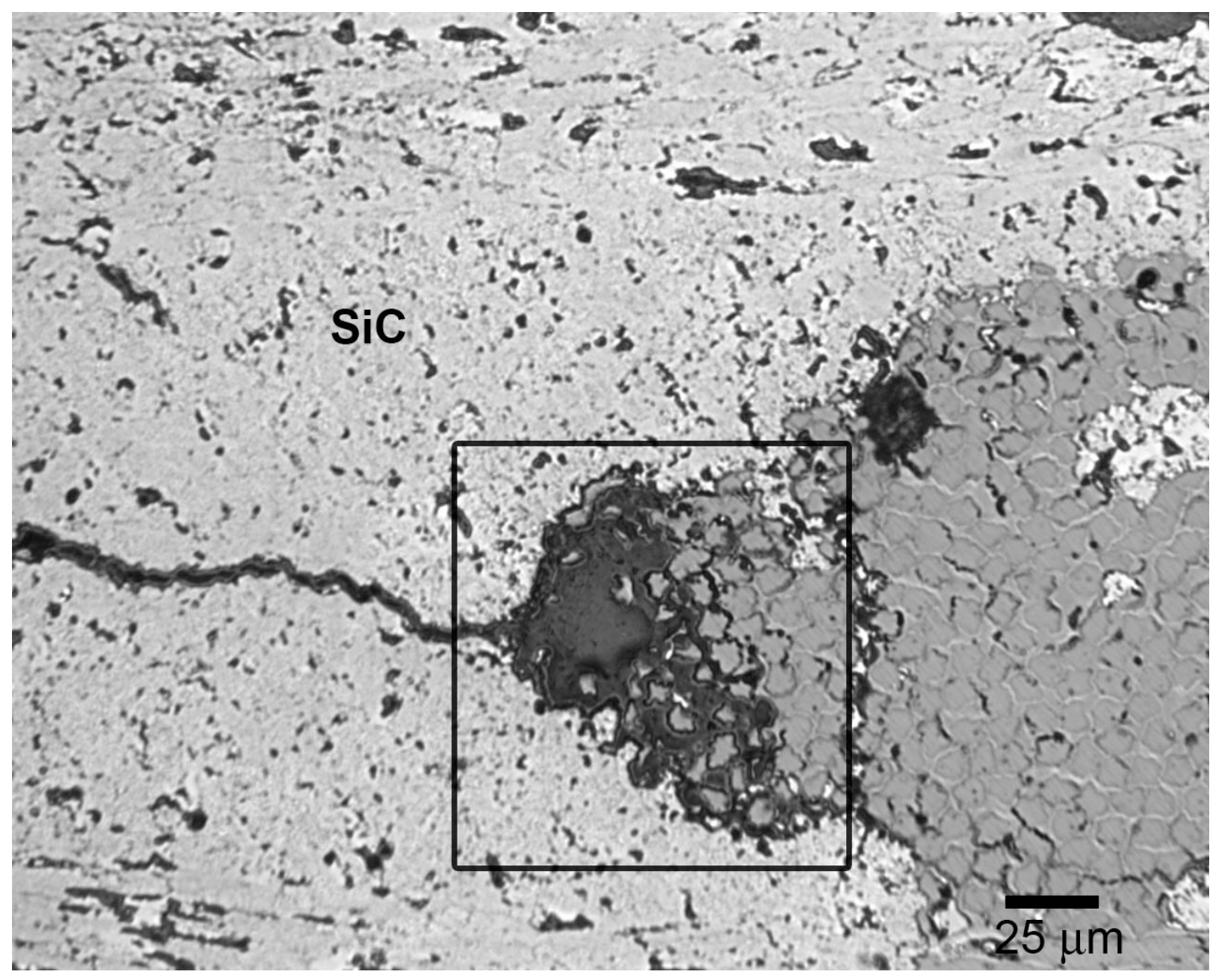

Figure 10(b). Oxidation cavity in a longitudinal fiber bundle for RCC-P3/SiC oxidized at $1100^{\circ} \mathrm{C}$ for $1 \mathrm{~h}$.

The specimen oxidized at $900^{\circ} \mathrm{C}$ showed only one clear cavity, as shown in Fig. 11. The oxidation voids observed in Figs. 9-11 differ significantly from the processing void in Fig. 2(c). First the oxidation voids are associated with a crack/path to the surface and located at the $\mathrm{SiC} /$ carbon-carbon interface. Second the oxidation voids have 'rough' edges due to selective attack of bordering fibers.

Figs. 10(b) and 11 show regions of unoxidized matrix. It appears that in the RCC P$3 / \mathrm{SiC}$ samples, the matrix is not attacked preferentially to the fibers, as opposed to the RCC P-3 samples. A possible explanation for this is that the high temperature necessary for forming the $\mathrm{SiC}$ conversion coating further graphitizes the matrix material, giving it a similar oxidation resistance to the fibers. 


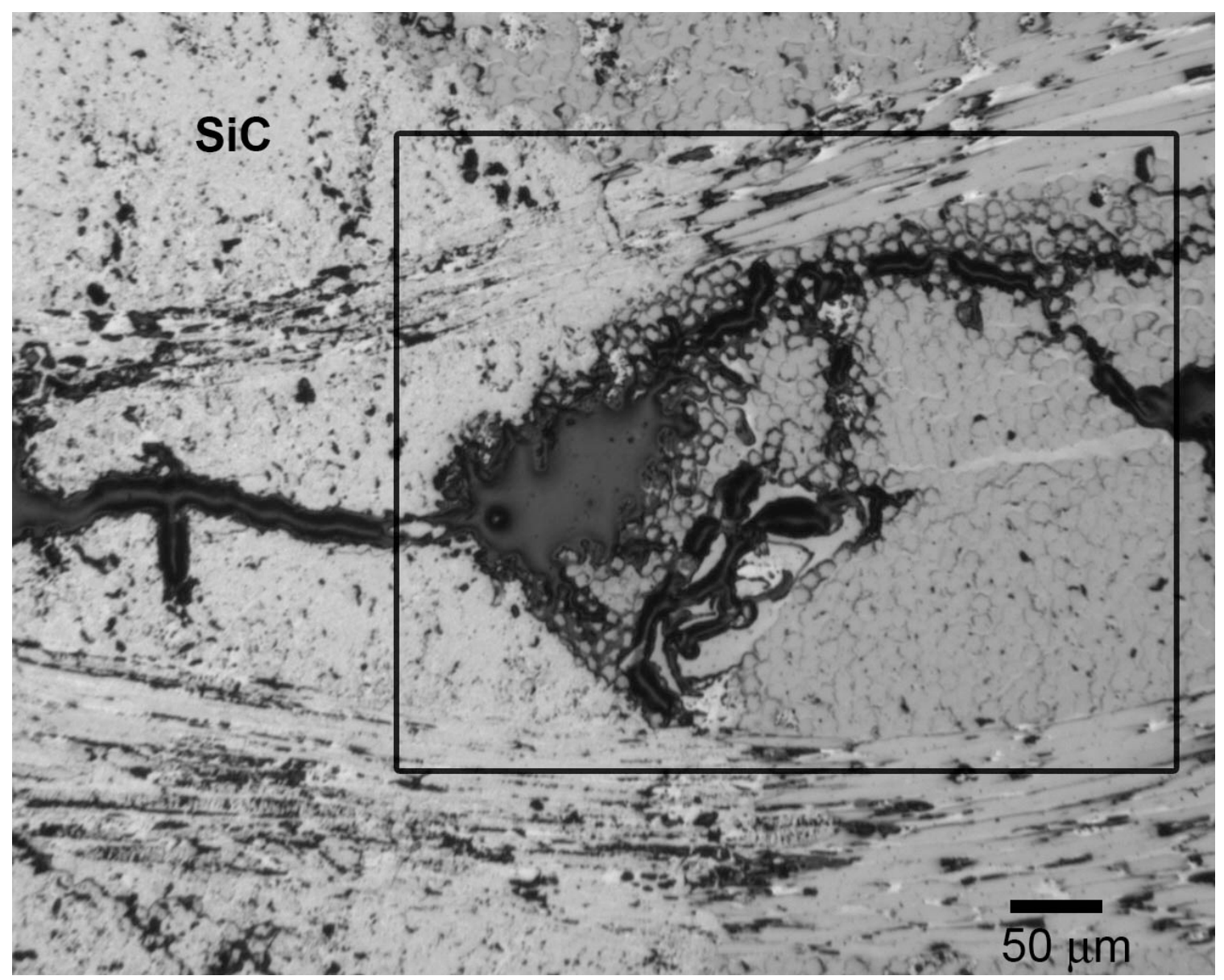

Figure 11. Cavity formed in RCC P-3/SiC after oxidation at $900^{\circ} \mathrm{C}$ for $1 \mathrm{~h}$.

Clear oxidation damage on the $700^{\circ} \mathrm{C}$ and $500^{\circ} \mathrm{C}$ specimens could not be found at these magnifications. Oxidation at these lower temperatures is chemical reaction-controlled and is very likely too slow to observe after a $1 \mathrm{~h}$ exposure of SiC-protected sample.

\subsection{Results and Discussion: Arc-Jet Oxidation of RCC-P3/SiC/TEOS/Sealant with Drilled Holes}

In a previous study [12] a standard $7.1 \mathrm{~cm}$ diameter arc-jet specimen was run for a cumulative $3.5 \mathrm{hrs}$ at $1538^{\circ} \mathrm{C}\left(2800^{\circ} \mathrm{F}\right)$ in the NASA JSC Arc-jet. A grid of $0.8 \mathrm{~mm}$ diameter holes was drilled in this specimen through the SiC coating, stopping at the carbon/carbon. Extensive oxidative consumption occurred near the holes, as has been discussed. However, through-thickness cracks away from the holes do not show a clear 
path to oxidation cavities, as shown in Fig. 12. It is important to note that this specimen had the full oxidation protection - a SiC conversion coating, TEOS-derived $\mathrm{SiO}_{2}$, and two applications of the sodium silicate based glass. Nonetheless, the lack of oxidation damage at $1538^{\circ} \mathrm{C}$ is significant and consistent with the limited oxidation seen in furnacetreated specimens at $1500^{\circ} \mathrm{C}$.

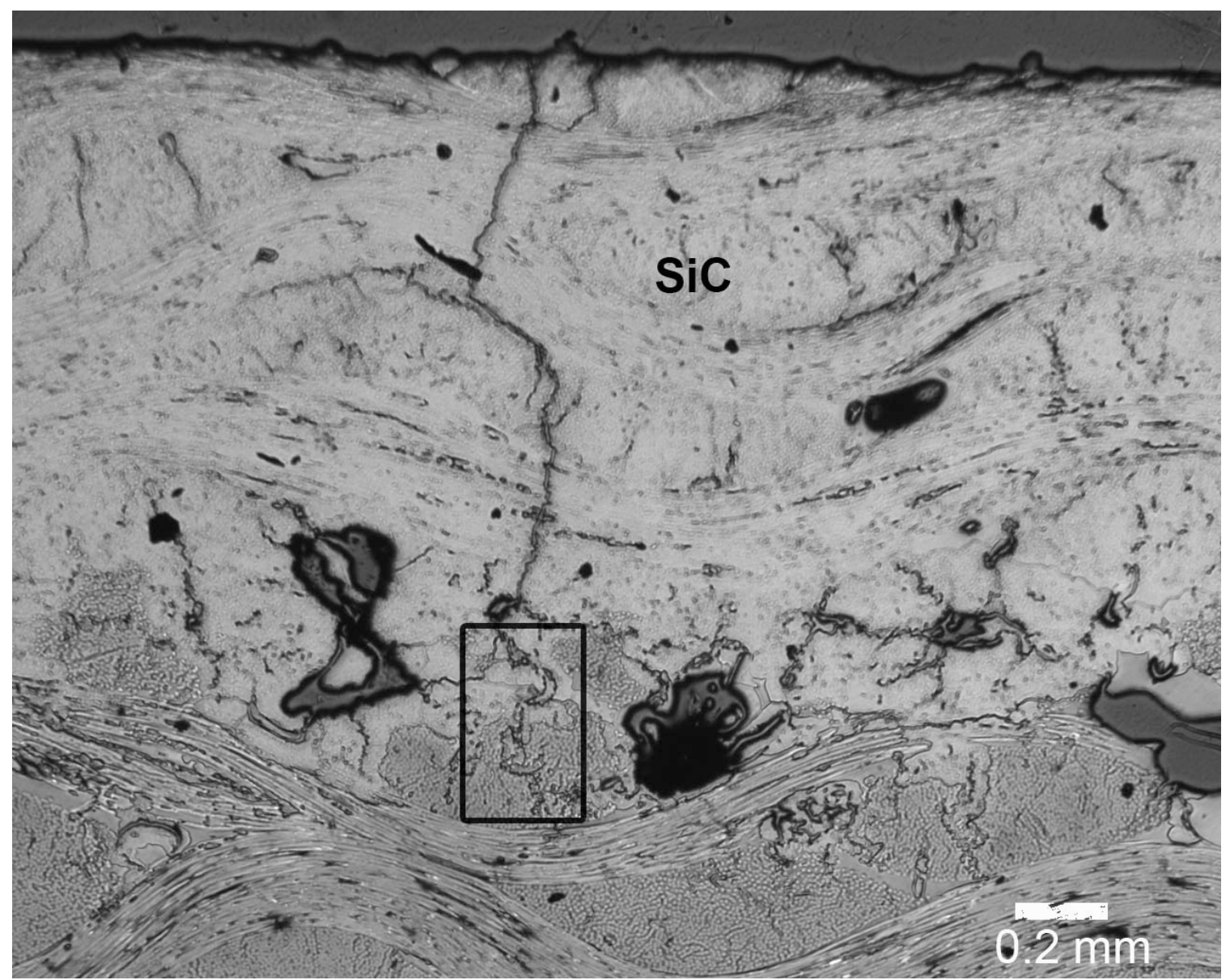

Figure 12. Through thickness crack on RCC-P3/SiC/TEOS/Sealant specimen after a total of $3.5 \mathrm{~h}$ in the arc-jet at $1538^{\circ} \mathrm{C}$. Note there is no clear oxidation damage below the crack.

The regions below a large drilled hole showed substantial oxidation, as would be expected (Fig. 13(a)). The cavity is roughly spherical on this macroscopic scale, which suggests uniform attack in all directions, as expected for a situation where diffusion 
control dominates. However a closer examination of the cavity walls indicates consumption is not truly uniform and there is clear evidence of preferential attack (Figs. 13(a) and (b)). Thus even at high temperatures where gas phase diffusion control dominates, there is selective attack within the carbon/carbon, indicating that rates of chemical reaction must still be important in the overall mechanism. Fig. 13(b) shows a close-up of the edge of one of the oxidation cavities. Note first the presence of denuded fibers in both the longitudinal and transverse directions. This is due to preferential attack at the fiber/matrix interface. The arrow points to a bundle of transverse fibers with denuded fibers along the edges and also along cracks into the bundle. Oxidation occurs preferentially down cracks and at the fiber edges.

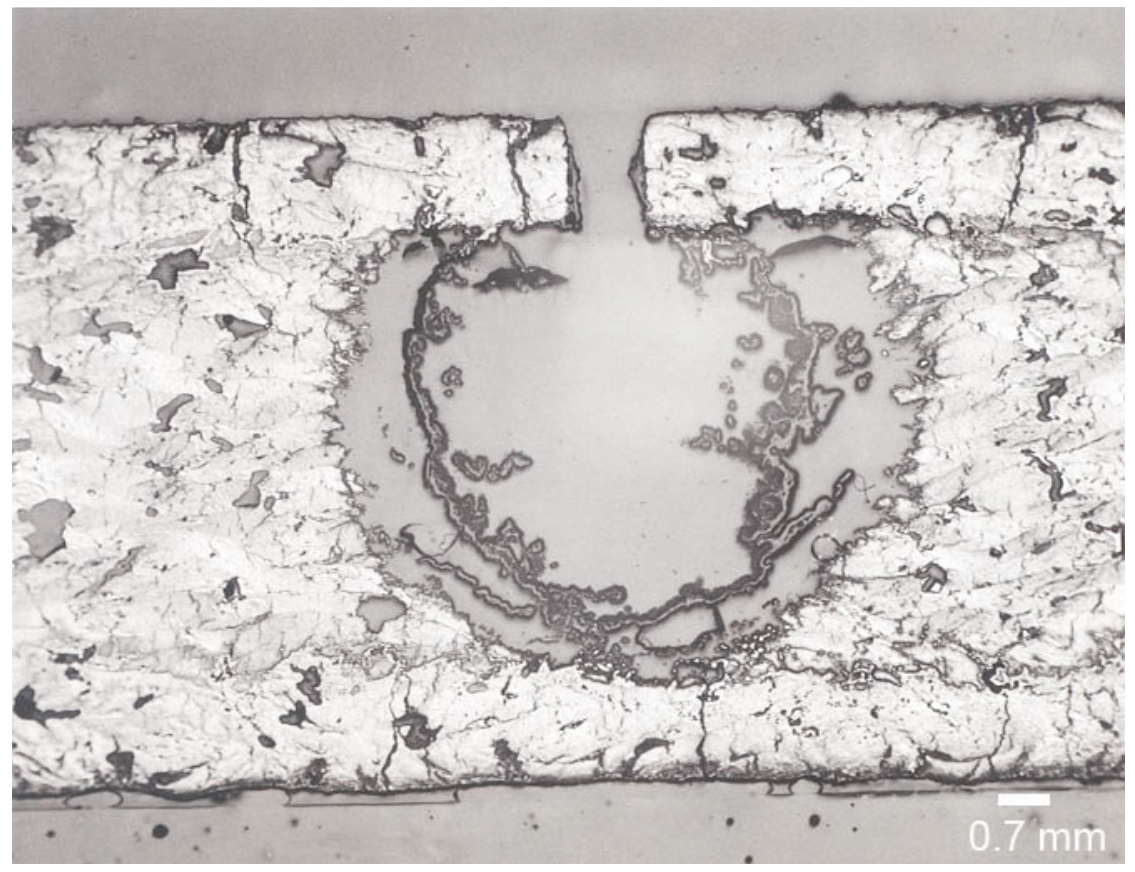

Figure 13(a). Oxidation through a pinhole intentionally drilled in RCC. This RCC$\mathrm{P} 3 / \mathrm{SiC} / \mathrm{TEOS} /$ Sealant specimen was oxidized for a total of $3.5 \mathrm{~h}$ in the arc-jet at $1538^{\circ} \mathrm{C}$. 


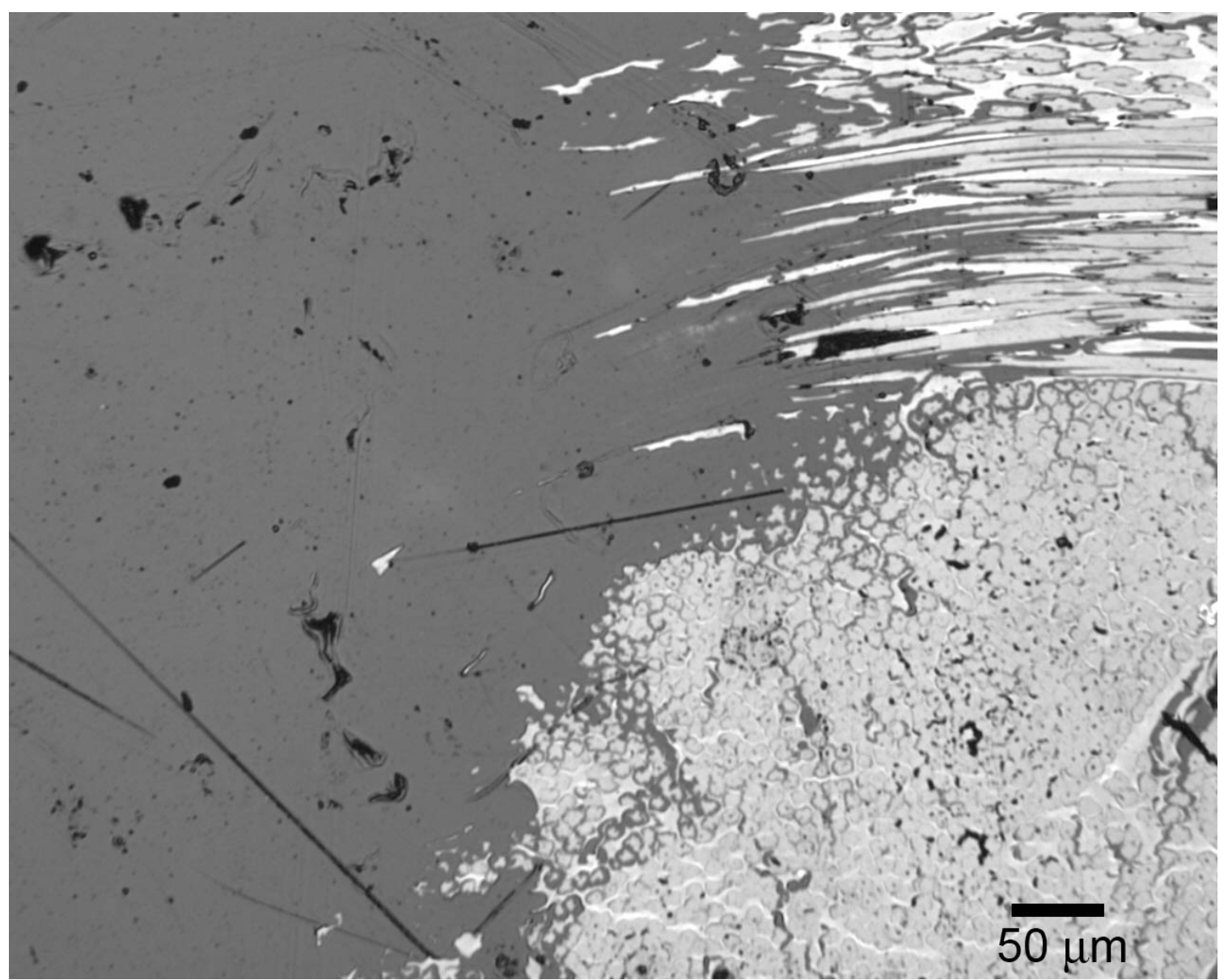

Figure 13(b) High-magnification photo of the edge of cavity in Fig. 13(b). The arrow points to a transverse fiber bundle with internal cracks, which are likely oxygen paths. This RCC-P3/SiC/TEOS/Sealant specimen was oxidized for a total of $3.5 \mathrm{~h}$ in the arc-jet at $1538^{\circ} \mathrm{C}$

\subsection{Results and Discussion: Arc-Jet Oxidation of RCC-P3/SiC/TEOS/Sealant with Impact Damage}

In this part of the study, a sectioned piece of RCC is examined after impact damage. Damage was intentionally induced with hydraulically controlled steel ball, $\sim 1.27 \mathrm{~cm}$ diameter, in the center of a standard $7.1 \mathrm{~cm}$ arc-jet test disc. This created an indentation and substantial cracking of the $\mathrm{SiC}$ coating. Post-test cross sectioning showed that cracks propagated into the carbon-carbon substrate around the fiber bundles. The specimen was 
then exposed to the arc-jet at JSC for three cycles at $1538^{\circ} \mathrm{C}\left(2800^{\circ} \mathrm{F}\right), 4788 \mathrm{~Pa}(100$ PSF), 900 seconds each cycle. There were numerous paths for oxidation of the carbon/carbon and this sample illustrates severe oxidation of carbon/carbon under arc-jet conditions.

Figs. 14(a)-(c) shows an exposed region of carbon/carbon. Note the channels between fiber bundles with denuded fibers. Figure 14(b) shows a higher magnification view.. In Fig. 14(c) a large section of matrix which is intact after the oxidation treatment is noted. The matrix is graphitized during processing at a high temperature, so it should exhibit similar oxygen reactivity to the fibers. These micrographs suggest that oxidation occurs along oxygen paths created by cracks. Fibers are attacked at the fiber/matrix interface, denuded and are eventually consumed, enlarging the cracks further. 


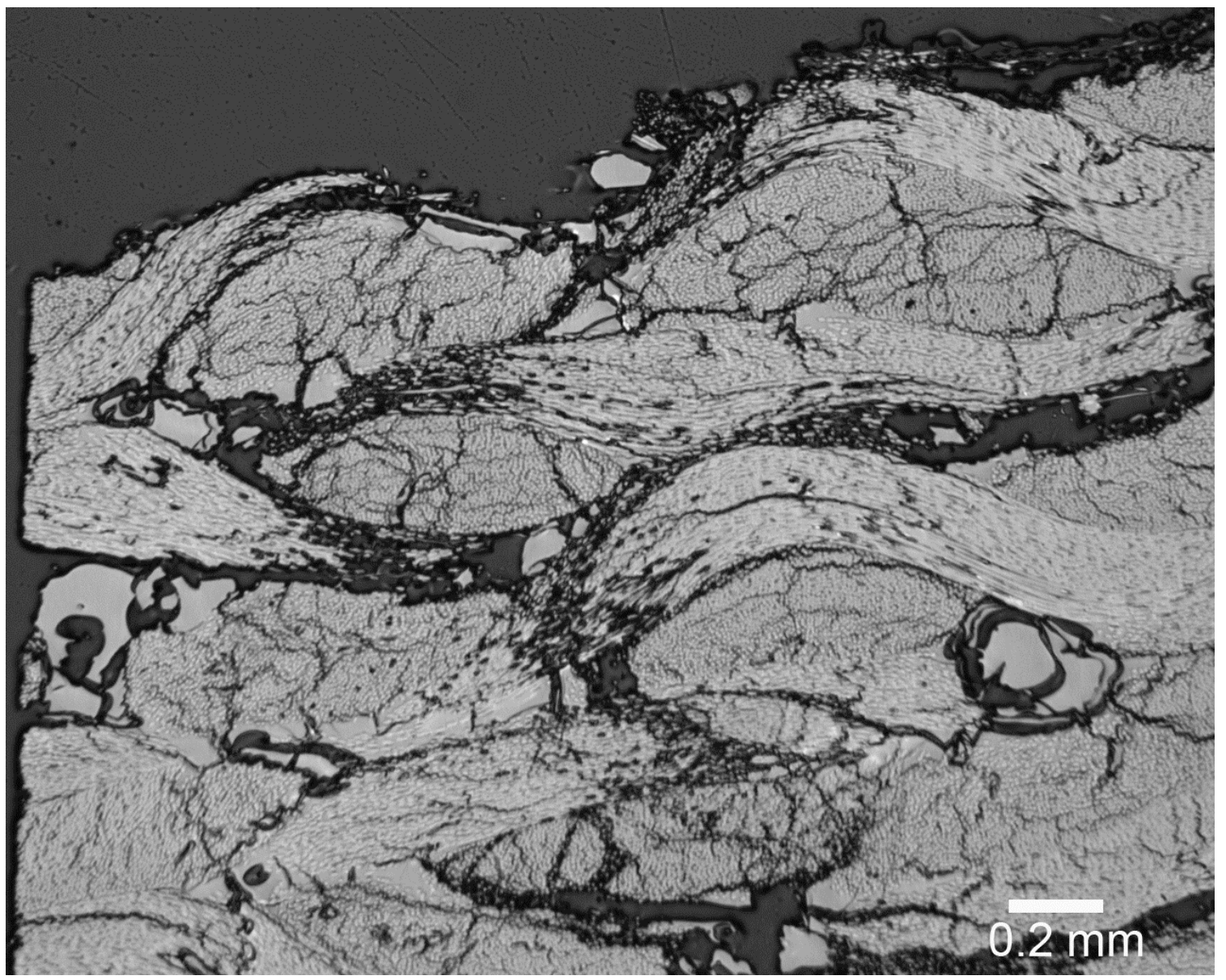

Figure 14(a). Cross-sectional view showing impact damaged RCC. This RCC-

$\mathrm{P} 3 / \mathrm{SiC} / \mathrm{TEOS} / \mathrm{Sealant}$ specimen was oxidized for three $900 \mathrm{~s}$ cycles in the arc-jet at $1538^{\circ} \mathrm{C}$. Arc impinged on the top. 


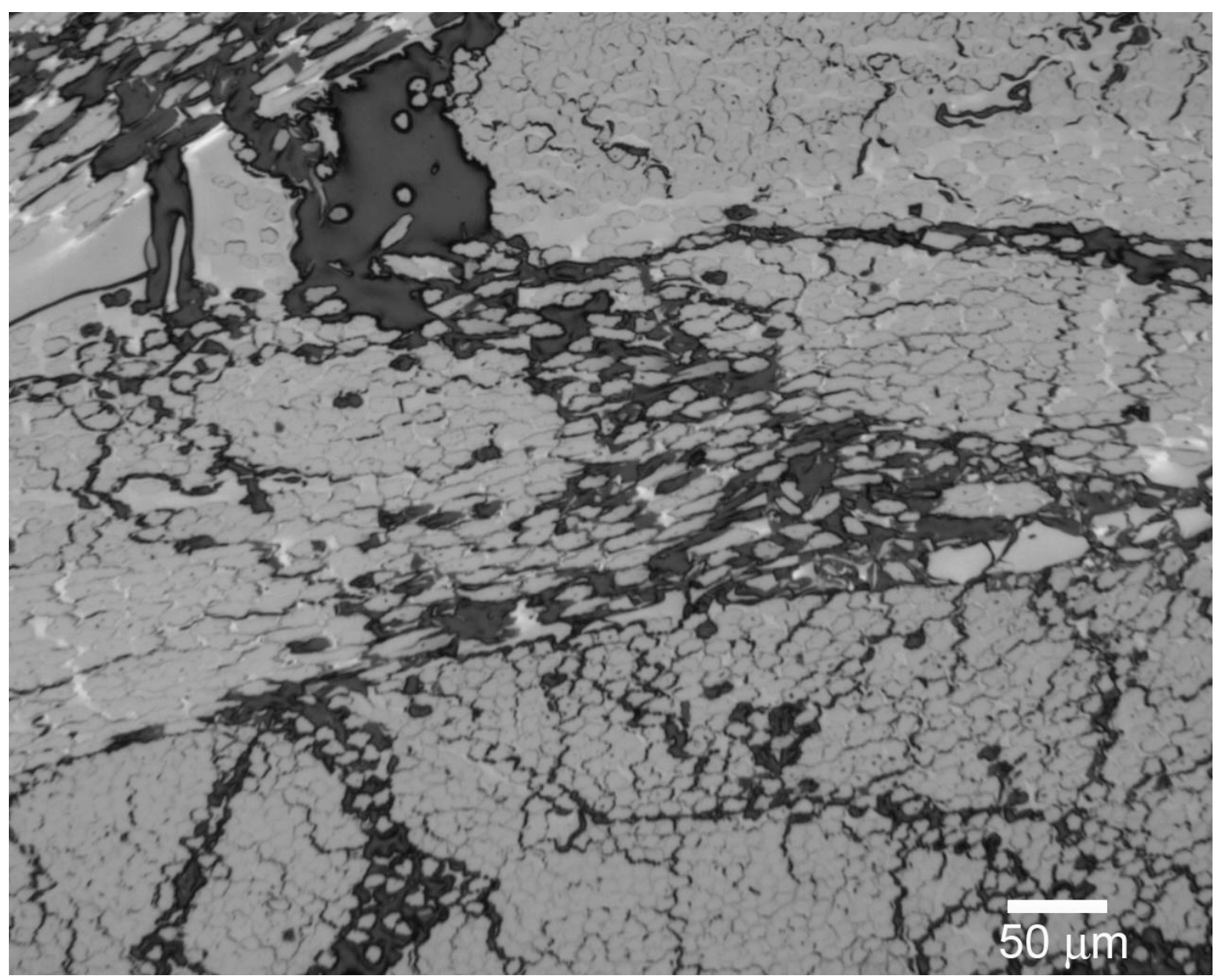

Figure 14(b). Cross-sectional view showing channels of oxidation and denuded fibers.

This RCC-P3/SiC/TEOS/Sealant specimen was oxidized for three $900 \mathrm{~s}$ cycles in the arcjet at $1538^{\circ} \mathrm{C}$. Arc impinged on the top. 


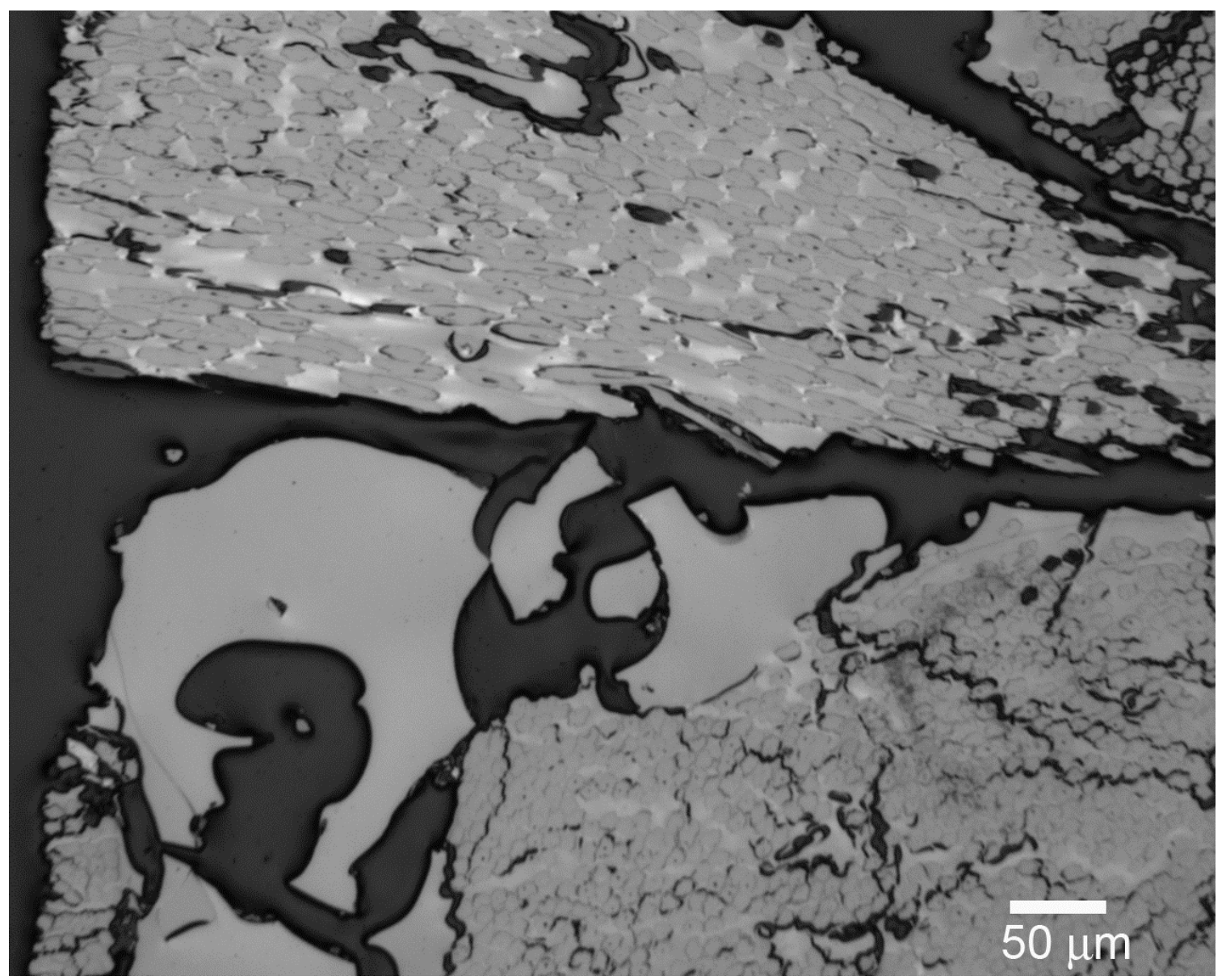

Figure 14(c). Cross-section view showing large regions of intact matrix. This RCC$\mathrm{P} 3 / \mathrm{SiC} / \mathrm{TEOS} /$ Sealant specimen was oxidized for three $900 \mathrm{~s}$ cycles in the arc-jet at $1538^{\circ} \mathrm{C}$. Arc impinged on the top.

\section{Conclusions}

Based upon these studies, a number of conclusions can be drawn about the oxidation behavior of RCC.

1. Oxidation of the carbon fibers leads to denuded fibers and a pointed morphology. The interface between the fiber and the matrix appears to be oxidized preferentially as compared to the core of the fiber. 
2. The uncoated RCC P-3 specimen oxidized at $800^{\circ} \mathrm{C}$ for $0.5 \mathrm{~h}$ showed fairly uniform attack throughout, indicative of chemical reaction rate control; whereas the $1100^{\circ} \mathrm{C}$ shows more attack along the edge, indicative of gas phase diffusion rate control.

3. In the RCC P-3 material, it appears the matrix is attack preferentially as it could not be located in the post-oxidation 800 and $1100^{\circ} \mathrm{C}$ samples.

4. In the SiC-coated specimens, oxidation appears greatest at 1100 and $1300^{\circ} \mathrm{C}$; less at $900^{\circ} \mathrm{C}$ and $1500^{\circ} \mathrm{C}$; and limited at 500 and $700^{\circ} \mathrm{C}$. At $1500^{\circ} \mathrm{C}$ there is the most oxidation of the $\mathrm{SiC}$, which can seal the system against oxygen ingress. The extensive oxide formed appeared to have dripped or spalled off the $1500^{\circ} \mathrm{C}$ samples. The limited attack at the lower temperatures $\left(500-700^{\circ} \mathrm{C}\right)$ is expected from kinetic barriers to carbon oxidation.

4. In the SiC-coated specimens, samples exposed at higher temperature samples (900$1300^{\circ} \mathrm{C}$ ) show small oxidation voids formed below a crack at the $\mathrm{SiC} /$ carbon interface. This is indicative of diffusion-controlled oxidation. This is consistent with the literature. However preferential attack of the fiber edges over the bulk was noted even at $1538^{\circ} \mathrm{C}$. This indicates that even in the diffusion control regime, there is still some surface reaction sensitivity

5. An oxidation void is characterized by delineated fibers along the edge and pointed fibers with no surrounding matrix, which clearly distinguishes it from a processing void.

6. Oxidative consumption of carbon/carbon occurs first by transport of oxygen down cracks, denuded fibers and eventual consumption of fibers along the cracks.

\section{Acknowledgements}

It is a pleasure to thank Donald Humphrey, QSS Inc./NASA Glenn Research Center and John Holchin, Summer Student/NASA Glenn Research Center for the laboratory RCC

oxidation tests. Gratitude is also expressed to Myles McQuater, formerly QSS Inc./NASA 
Glenn Research Center for the metallography and Terry McCue, QSS Inc./NASA Glenn Research Center for the SEM work. 


\section{References}

1. Walker PL Jr., Rusinko F Jr., Austin LG: In Advances in Catalysis and Related Subjects, New York, Academic Press, 1959; 133-221.

2. McKee DW. Oxidation behavior and protection of carbon/carbon composites. Carbon 1987; 25(4): 551-557.

3. Crocker P, McEnaney B. Oxidation and fracture of a woven 2D carbon-carbon composite. Carbon 1991; 29(7): 881-885.

4. Shemet ZSh, Pomytkin AP, Neshpor VS. High temperature oxidation behaviour of carbon materials in air. Carbon 1993; 31(1): 1-6.

5. Han JC, Je XD, Du SY. Oxidation and ablation of 3D carbon-carbon composite at up to $3000^{\circ} \mathrm{C}$. Carbon $1995 ; 33(4): 473-478$.

6. Glime WH, Cawley, JD. Oxidation of carbon fibers and films in ceramic matrix composites: A weak link process. Carbon 1995; 33(8): 1053-1060.

7. Rodríguez-Mirasol J, Thrower P, Radovic LR. On the oxidation resistance of carboncarbon composites: Importance of fiber structure for composite reactivity. Carbon 1995; 33(4): 545-554.

8. Lamouroux F, Bourrat X, Naslain R, Sevely J. Structure/oxidation behavior relationship in the carbonaceous constituents of $2 \mathrm{D}-\mathrm{C} / \mathrm{PyC} / \mathrm{SiC}$ composites. Carbon 1993; 31(8): 1273-1288.

9. Halbig MC, Cawley JD. Modeling the environmental effects on carbon fibers in a ceramic matrix at oxidizing conditions. Proceedings of $24^{\text {th }}$ Annual Cocoa Beach 
Conference and Exposition: An International Conference on Engineering Ceramics, Cocoa Beach (Florida, USA). American Ceramic Society, 2000.

10. Curry DM, Cunningham JA, Frahm JR. Space shuttle orbiter leading edge structural subsystem thermal performance. AIAA-82-0004. AIAA 20 ${ }^{\text {th }}$ Aerospace Sciences Meeting, Orlando (Florida, USA). AIAA, 1982.

11. Becker PR. Leading-edge structural material system of the space shuttle. Ceram. Bull. 1981; 60(11): 1210-1214.

12. Jacobson NS, Leonhardt TA, Curry DM, Rapp RA., Oxidative attack of carbon/carbon substrates through coating pinholes. Carbon 1999; 37: 411-1419.

13. Rochelle WC, Battley HH, Grimaud JE, Tillian DJ, Murray LP, Lueke WJ, Heaton TM. Orbiter TPS development and certification testing at NASA/JSC $10 \mathrm{MW}$ atmospheric reentry materials and structures evaluation facility. AIAA-83-0147. AIAA aerospace sciences meeting, Reno (Nevada, USA). AIAA 1983.

14. Williams SD, Curry DM, Pham VT, Chao D. Analysis of the shuttle orbiter reinforced carbon-carbon oxidation protection system. NASA TM-104792, 1994.

15. Opila EJ, Jacobson NS. Corrosion of ceramics. In Schutze MD, editor. Corrosion science and degradation of materials, Vol. 11-Volume 19 of the materials science and technology. Wiley-VCH, Weinheim (Germany), 2000; 327-388. 